\title{
Mixing-layer height retrieval with ceilometer and Doppler lidar: from case studies to long-term assessment
}

\author{
J. H. Schween ${ }^{1}$, A. Hirsikko ${ }^{2}$, U. Löhnert ${ }^{1}$, and S. Crewell ${ }^{1}$ \\ ${ }^{1}$ Inst. f. Geophysics and Meteorology, Univ. of Cologne, Cologne, Germany \\ ${ }^{2}$ Forschungszentrum Jülich $\mathrm{GmbH}$, Institut für Energie-und Klimaforschung: \\ Troposphäre (IEK-8), Jülich, Germany \\ Correspondence to: J. H. Schween (jschween@uni-koeln.de) \\ Received: 14 February 2014 - Published in Atmos. Meas. Tech. Discuss.: 30 April 2014 \\ Revised: 18 September 2014 - Accepted: 24 September 2014 - Published: 8 November 2014
}

\begin{abstract}
Aerosol signatures observed by ceilometers are frequently used to derive mixing-layer height (MLH) which is an essential variable for air quality modelling. However, Doppler wind lidar measurements of vertical velocity can provide a more direct estimation of MLH via simple thresholding. A case study reveals difficulties in the aerosol-based MLH retrieval during transition times when the mixing layer builds up in the morning and when turbulence decays in the afternoon. The difficulties can be explained by the fact that the aerosol distribution is related to the history of the mixing process and aerosol characteristics are modified by humidification. The results of the case study are generalized by evaluating one year of joint measurements by a Vaisala CT25K and a HALO Photonics Streamline wind lidar. On average the aerosol-based retrieval gives higher MLH than the wind lidar with an overestimation of MLH by about $300 \mathrm{~m}(600 \mathrm{~m})$ in the morning (late afternoon). Also, the daily aerosol-based maximum MLH is larger and occurs later during the day and the average morning growth rates are smaller than those derived from the vertical wind. In fair weather conditions classified by less than 4 octa cloud cover the mean diurnal cycle of cloud base height corresponds well to the mixing-layer height showing potential for a simplified MLH estimation.
\end{abstract}

\section{Introduction}

The atmospheric boundary layer (ABL) is the lowest part of the atmosphere that is in contact with the Earth's surface (American Meteorological Society, 2013). The mixing layer is a type of $\mathrm{ABL}$ where exchange processes between the
Earth's surface and the atmosphere occur via turbulent mixing (see e.g. Oke, 1987; American Meteorological Society, 2013). Gaseous and particulate constituents emitted from the surface become well mixed within the ML which is capped by a temperature inversion or statically stable layer of air. Therefore, aerosol particle concentration is high in the mixing layer whereas further up in the free troposphere aerosol concentrations are generally much lower. Atmospheric pollutants are dispersed within the ML, and thus mixing-layer height (MLH) is an important parameter for air quality applications. Any model that attempts to predict concentrations needs MLH as a parameter or must be able to describe its evolution (e.g. Collier et al., 2005; White et al., 2009). Furthermore, in a convective boundary layer, cumulus clouds can only develop if the MLH reaches the convective condensation level, making it thus a relevant quantity for numerical weather prediction.

Vertical mixing in the ABL can occur due to surface heating and resulting buoyancy but also due to wind shear. The first leads to a convective boundary layer which occurs nearly every day and which is described in the following. Daytime ABL turbulent mixing is driven by solar radiation energy, which - to a major part - is absorbed by the Earth's surface and re-emitted to the atmosphere in the form of long-wave terrestrial radiation and turbulent fluxes of latent and sensible heat (i.e. convection, Stull, 1988; Garratt, 1994). The formation of clouds reduces the incoming solar radiation at the surface and thus the turbulent heat fluxes from the surface into the atmosphere. This introduces a feedback mechanism modulating the exchange between surface and atmosphere. After sunset on days with strong local and weak synoptical forcing, 
convection decays and a neutral or slightly stable layer forms, called the residual layer (RL). At night the emission of longwave radiation by the surface leads to strong cooling and the formation of a stable nocturnal boundary layer (NBL) close to the surface and below the RL. In low wind speed situations stratification of the NBL can be very strong, leading to a decoupling of the layer above and as a consequence to the formation of the so-called nocturnal low-level jet

(Garratt, 1994), which may induce intermittent turbulent mixing (Banta et al., 2006). In the case of moderate surface winds during night a shallow nocturnal mixing layer may be induced by surface roughness and stored heat especially in urban areas (Souch and Grimmond, 2006). Strong winds are usually connected to strong shear especially close to the surface and thus also induce turbulent mixing which can reach even during night heights similar to those of a convective ML.

A number of methods exist to determine the MLH from different measurements (Seibert et al., 2000). Most of them are based on proxies for the mixing process, such as temperature, humidity or Richardson number. These parameters are frequently used in radiosonde-based retrievals, which are often considered to be the most reliable as they are based on in situ measured parameters, and are therefore used as reference in several studies (e.g. Eresmaa et al., 2006; Sicard et al., 2006; Münkel et al., 2007; O'Connor et al., 2010). However, determination of the MLH from radiosonde data is not that straightforward because no unambiguous separation between ML and the atmosphere above might be found (Seibert et al., 2000). Additionally, radiosondes measure properties along their flight path and their data might not be representative for the atmospheric column above the measurement site. Due to the fact that a radiosonde follows the horizontal wind during its ascent, it tends to move into regions with convergence and avoids regions with divergence. As a result radiosonde profiles are biased towards properties of rising plumes in convective situations. In addition, a major shortcoming of radiosondes for MLH estimation is their coarse temporal resolution.

Many of the radiosonde drawbacks can be overcome by continuously operating ground-based remote sensing instruments. Lidar (Light Detection and Ranging) systems have been used for atmospheric research since the 1960s (Weitkamp, 2005). An aerosol lidar determines the aerosol backscatter coefficient $\beta$ which depends on number concentration, size and optical properties of the aerosol particles. Assuming that the main source for aerosol and its precursors is at the surface, turbulent mixing will lead to a uniform high aerosol concentration in the ML and a distinct gradient to much lower concentrations in the atmosphere above. Thus it should be possible to derive MLH from lidar by using the aerosol backscatter as a proxy. A number of different lidar-based algorithms exist to detect MLH (see e.g. Emeis et al., 2008). They are based on evaluating the gradient of the backscatter profile (Endlich et al., 1979), its logarithm (i.e. the relative gradient) (Senff et al., 1996), fitting to a function
(Steyn et al., 1999; Eresmaa et al., 2012), application of the Haar wavelet analysis (Davis et al., 2000; Brooks, 2003; Haij et al., 2006), or a threshold for the backscatter (e.g. Harvey et al., 2013). Even though advantages and disadvantages of different methods have been investigated by several studies (see e.g. Sicard et al., 2006; Haij et al., 2007; Eresmaa et al., 2012; Haeffelin et al., 2012), no consensus on a specific algorithm has been reached yet.

Lidar ceilometers are robust low-power, low-cost and lowmaintenance lidars designed to determine the cloud base height (ceiling) but also provide the backscatter profile, though with less sensitivity than a lidar. Several studies have proposed that ceilometer-measured backscatter profiles can be used to derive the MLH (e.g. Münkel et al., 2007; Eresmaa et al., 2006, 2012). Many airports, weather services, research institutions etc. operate ceilometers (see http://www.dwd.de/ ceilomap), and therefore, attempts are made to use them as a network for aerosol retrieval (e.g. Wiegner et al., 2014) but also of MLH observations (e.g. Haij et al., 2007; Haeffelin et al., 2012).

Doppler lidars offer a direct approach to investigate the ABL mixing (e.g. Cohn and Angevine, 2000; Hogan et al., 2009). Instead of measuring a proxy for the vertical mixing, Doppler lidars can measure directly the vertical air velocity. Engineering progress but also growth of the wind energy industry in the last two decades have led to the development of affordable and robust Doppler lidar systems (e.g. Pearson et al., 2010). MLH can be estimated by using a threshold value for the vertical velocity standard deviation $\sigma_{w}$ (e.g Tucker et al., 2009; Pearson et al., 2010; Barlow et al., 2011; Träumner et al., 2011). Another method is to use turbulent energy dissipation rate as proposed by O'Connor et al. (2010). This method is based on the assumption that measurements take place in the inertial subrange. However, the effort to ensure this is rather high (investigation of turbulent spectra) and reduces the universality of the method. Martucci et al. (2012) identify the MLH as the level of a distinct negative gradient in the $\sigma_{w}$ profile. This is somehow a contradiction to the semi-theoretical profiles which show a smooth decay with more or less constant gradients towards the top of the ML (Lenschow et al., 1980; Sorbjan, 1989). In their multi-sensor approach for a boundary layer classification Harvey et al. (2013) use the second derivative of the vertical velocity variance with respect to height: if the profile is convex in the lower half of the ABL it is a ML with mixing originating from the surface. Träumner et al. (2011) discuss several methods based on the semi-theoretical $\sigma_{w}$ profile as proposed by Lenschow et al. (1980). They find that the use of a threshold for $\sigma_{w}$ is the most robust method.

Currently, only relatively few comparisons of MLH retrievals between aerosol and Doppler lidars exist. A qualitative comparison of Doppler lidar-derived vertical wind speed and MLH derived from aerosol backscatter profiles was performed by Baars et al. (2008) for a time period of 3 days. They find that aerosol-based MLH retrievals agree with the 
height of the layer within which the largest vertical wind speeds occur. Tucker et al. (2009) test different retrievals based on vertical velocity variance, horizontal wind shear and lidar backscatter from a ship-based Doppler lidar during a 44-day campaign in the Gulf of Mexico. A comparison of 99 selected best MLHs derived from different methods and radiosondes gives a correlation of 0.87. During a 10week campaign in a tropical rainforest Pearson et al. (2010) find significantly lower MLH derived from aerosol backscatter than those retrieved from wind lidar, which they attribute to aerosol particle growth within humid layers, gradients in the residual layer, and clouds. A 1-month campaign in London, UK, described by Barlow et al. (2011) shows good agreement between aerosol- and vertical wind based MLH during night but reveals a systematic underestimation of the aerosol-based MLH during daytime. Träumner et al. (2011) investigate 12 days of data from different campaigns in central Europe. A Doppler wind lidar is used to derive MLH from aerosol backscatter and vertical wind speed. Comparison of both retrievals shows a high correlation $(R=0.91)$ but also large scatter with individual differences in the order of $500 \mathrm{~m}$, which are attributed to the fact that the turbulencebased height gives the current extent of the ML whereas the aerosol-based height gives a measure of past MLH.

In general, studies agree that MLH is only reliably retrieved from aerosol backscatter during noon hours when the convective boundary layer is fully developed and topped by the clean, free troposphere (e.g. Eresmaa et al., 2012; Träumner et al., 2011) Nevertheless, some recent studies investigated the climatology of e.g. the maximum MLH or the ML growth rate (e.g. Baars et al., 2008; Cimini et al., 2013; Korhonen et al., 2014) not taking into account any limitations of the MLH retrieval during certain conditions. Especially, evaluating the growth rate between some hours after sunrise and maximum MLH assumes that there are no limitations of the MLH retrieval during this time. Therefore a quantification of the errors of aerosol-based MLH retrievals is necessary. MLH retrieval based on Doppler wind lidar gives the opportunity to evaluate this on high temporal resolution and over a long time period, if an automated system is used.

The aim of this work is to estimate and compare MLH derived from stand-alone ceilometer aerosol particle backscatter profiles and from Doppler lidar vertical velocity standard deviation profiles based on 1 year of continuous observations. The vertical wind speed based MLH retrieval may be seen as a reference as it is based on the variable that causes the vertical mixing, whereas aerosol-based retrievals use the aerosol backscatter as a proxy. In this way, the potential performance of a low-cost ceilometer network for MLH estimation can be assessed.

\section{Instruments and retrievals}

The following analysis is based on observations by a Vaisala CT25K lidar ceilometer and a HALO Photonics Doppler lidar operated continuously at the Jülich ObservatorY for Cloud Evolution (JOYCE, http://geomet.uni-koeln. de/joyce/) in Germany at $50^{\circ} 54^{\prime} \mathrm{N}, 6^{\circ} 24^{\prime} \mathrm{E}$ and $111 \mathrm{~m}$ above mean sea level. The site has a typical central European climate. The 30-year average precipitation for the region shows two minima in April (about $60 \mathrm{~mm}$ ) and September (about $70 \mathrm{~mm}$ ) respectively with September slightly wetter. Maximum precipitation occurs typically in July and December (both around $81 \mathrm{~mm}$ ). Average temperatures have their minimum in January $\left(1.4{ }^{\circ} \mathrm{C}\right)$ and maximum in July $\left(17.5^{\circ} \mathrm{C}\right)$ (Deutscher Wetterdienst, 2011 and 2012). The CT25K ceilometer is available since the 1990s and can be considered as a typical low-cost network instrument. In order to test its performance with respect to the next generation of ceilometers, we perform an intercomparison with the Jenoptik CMH15K ceilometer over 3 months. The ceilometers are located within $4 \mathrm{~m}$ of each other, and the Doppler lidar is ca. $20 \mathrm{~m}$ apart. The instruments and the respective algorithms, i.e. "Structure of the atmosphere" (STRAT-2D Morille et al., 2007; Haeffelin et al., 2012), to derive MLH are described below. For simplicity the retrieved mixinglayer heights are denoted as $\mathrm{MLH}_{\text {aero }}$ and $\mathrm{MLH}_{\text {wind }}$ for the aerosol-based algorithm and the vertical wind based MLHs, respectively.

\subsection{Ceilometer}

\subsubsection{Vaisala CT25K}

The Vaisala CT25K ceilometer (e.g. Vaisala, 1999; Münkel et al., 2007) collects backscatter data with $15 \mathrm{~s}$ temporal and $30 \mathrm{~m}$ spatial resolution up to a height of $7.5 \mathrm{~km}$ whenever sufficient backscatter from aerosol or clouds occurs. It operates at $905 \mathrm{~nm}$ wavelength with average emitted laser pulse energy $1.6 \mu \mathrm{J}$. In order to increase the signal-to-noise ratio 65536 pulses are averaged to one backscatter profile. For further details of the instrument see Table 1 . The instrument software provides profiles of the attenuated backscatter coefficient $(\beta)$, which are subsequently input to STRAT-2D. The manufacturer states that backscatter can be used from the first range gate, because a full overlap is achieved by using the same telescope for transmitting and receiving (see also Münkel et al., 2007). Recently Wiegner et al. (2014) have shown for a single exemplar of the succeeding model CL51 that the first range gates up to $60 \mathrm{~m}$ are not reliable and that the internal overlap correction of the instrument leads to a systematic overestimation of up to $10 \%$ of backscatter in the range below $500 \mathrm{~m}$. In the following we will not use MLHs at least below $120 \mathrm{~m}$. The error due to the internal overlap correction is small and uncertain for the $\mathrm{CT} 25 \mathrm{~K}$ and therefore not considered here. 
Table 1. Comparison of the performance of the Vaisala CT25K and Jenoptik CHM15k ceilometers. $E$ is energy, noise factor is the square root of the number of pulses per profile, i.e. a measure for the increase in signal-to-noise ratio due to averaging over many pulses for one backscatter profile. The reduced backscatter is calculated from the wavelength using $v_{\text {mie }}=1.4$.

\begin{tabular}{lllcl}
\hline & CT25K & CHM15k & CHM15k/CT25K & CHM15k feature \\
\hline Wavelength $(\mathrm{nm})$ & 905 & 1064 & 1.18 & less energy per photon \\
E/pulse $(\mu \mathrm{J})$ & 1.6 & 8 & 5.00 & more power \\
Pulses/profile & 65536 & 105650 & 1.61 & more pulses \\
Aperture $\left(\mathrm{m}^{2}\right)$ & 0.0165 & 0.0154 & 0.93 & smaller aperture \\
Range gate length & 30 & 15 & 0.50 & shorter gates \\
\hline Mie backscatter (A. U.) & 7.26 & 5.78 & 0.80 & less backscatter \\
Noise factor & 256 & 325 & 1.27 & better noise reduction \\
\hline Emitted photons & & & 9.48 & more emitted \\
Received photons & & & 4.42 & more received \\
\hline
\end{tabular}

Table 2. Availability (in percent) of MLH retrievals from the wind lidar and ceilometer during the four seasons from December 2011 to November 2012.

\begin{tabular}{lccccc}
\hline & MAM & JJA & SON & DJF & all \\
\hline Wind lidar & 45 & 47 & 29 & 55 & 43 \\
Ceilometer & 40 & 44 & 31 & 43 & 40 \\
\hline
\end{tabular}

\subsubsection{Jenoptik CHM15k}

The CHM15k-Nimbus manufactured by Jenoptik GmbH, Germany, operates at $1064 \mathrm{~nm}$ wavelength and provides profiles of backscatter up to $15 \mathrm{~km}$ with a temporal and spatial resolution of $15 \mathrm{~s}$ and $15 \mathrm{~m}$, respectively. As for the CT25K, true achieved range is limited by sufficient aerosol backscatter. But as the instrument has more power, this range is typically larger than that of the CT25K (Heese et al., 2010). Because the optics of the laser and the receiving telescope are separated, sufficient overlap of both optical systems is reached only at a height of about $350 \mathrm{~m}$. Average pulse energy $(8 \mu \mathrm{J})$ and number of pulses averaged to one profile $\left(N_{\mathrm{P}} \simeq 105650\right)$ are higher than those of the Vaisala ceilometer leading to about 8.5 times more emitted photons (see Table 1 and Appendix A). As range gates are shorter and wavelength is larger, the number of backscattered photons reaching the receiving telescope is only about 4.4 times larger. This feature and the more sensitive receiver unit make the CHM15k a significantly advanced ceilometer compared to the CT25K.

The instrument has been operated in its current setup since August 2013 at JOYCE and provides range and overlap corrected backscatter in arbitrary units. In contrast to earlier studies (e.g. Heese et al., 2010; Wiegner and Geiß, 2012; Martucci et al., 2010) the latest instruments software version used in this study also comprises a correction for the sensitivity fluctuations of the photo avalanche diode of the receiver.
This correction significantly increases the temporal stability of retrieved backscatter profiles.

In order to retrieve attenuated backscatter coefficient profiles $\beta$ in appropriate units (i.e. $\mathrm{Sr}^{-1} \mathrm{~m}^{-1}$ ) the provided raw backscatter $\beta_{\text {raw }}$ has to be divided by aperture $A$, range gate length $\Delta r$ and the number of emitted photons $N_{\text {emit }}$ calculated from laser pulse energy and wavelength by use of Planck's relation. With every profile the instrument provides self-diagnosed state variables for laser $S_{\mathrm{L}}$, optics $S_{\mathrm{O}}$ and receiver $S_{\mathrm{R}}$ in dimensionless units. They are included as $K=S_{\mathrm{L}} \cdot S_{\mathrm{O}} \cdot S_{\mathrm{R}}$ to yield

$\beta=\frac{\beta_{\text {raw }}}{A \cdot \Delta r \cdot K \cdot N_{\text {emit }}}$.

As for the CT25K, this variable is then passed on to STRAT2D to calculate MLH.

\subsubsection{Mixing-layer height from ceilometer}

From several methods proposed in the literature for estimating the MLH based on aerosol backscatter profiles we selected the "Structure of the atmosphere" (STRAT-2D) algorithm (Morille et al., 2007; Haeffelin et al., 2012), which is freely available and thus well suited for network applications. As in most algorithms for MLH from lidar backscatter, this method uses the vertical aerosol backscatter gradient, whereby strong negative gradients can indicate the MLH. However, in order to guarantee a certain temporal consistency of the MLH detection and thus to exclude unphysical outliers, the 2-D version of this algorithm is based on a 2D edge detection method (Canny, 1986). It first calculates a gradient in the time-height domain and then further filters for typical edge properties, i.e. there must be a local maximum in the direction of the gradient and gradient pixels must be larger than a threshold or they must have neighbours larger than this threshold (for details see Haeffelin et al., 2012). 
Within the STRAT-2D algorithm the $\beta$ profiles are first smoothed using a Gaussian kernel with widths set to 1.2 range gate length $(30 \mathrm{~m})$ and 40 time steps $(15 \mathrm{~s})$ corresponding to a moving average over $108 \mathrm{~m}$ and $30 \mathrm{~min}$. Signalto-noise ratio (SNR) is calculated for each bin and values with $\mathrm{SNR}<1.3$ are not used in further analysis. STRAT2D then determines three candidates for MLH: the largest $\left(\mathrm{MLH}_{\text {large }}\right)$, the second largest gradient $\left(\mathrm{MLH}_{\text {second }}\right)$ and the lowest height gradient $\left(\mathrm{MLH}_{\text {low }}\right)$. From these three candidates the most probable one is selected depending on the time of the day: during night-time, i.e. from sunset until 3 hours after sunrise, the lowest height $\left(\mathrm{MLH}_{\text {low }}\right)$ is chosen. During daytime STRAT-2D tries to avoid that the decay of $\beta$ within clouds is misinterpreted as MLH. Therefore the relative difference of $\beta$ from $60 \mathrm{~m}$ above and $60 \mathrm{~m}$ below the respective candidate is determined. If this relative difference is larger than 0.9 the candidate is rejected. Finally the first valid candidate from the list $\left(\mathrm{MLH}_{\text {large }}, \mathrm{MLH}_{\text {second }}\right.$, $\left.\mathrm{MLH}_{\text {low }}\right)$ is returned as the final MLH. If no candidate is found, STRAT-2D returns the lowest valid range gate (i.e. $30 \mathrm{~m}$ ) as MLH which is not used in the further analysis.

\subsubsection{Ceilometer intercomparison}

In order to assess the consistency of MLH retrievals from aerosol lidar, the MLH estimates from the two ceilometers are compared. Backscatter data of both instruments from 16 August to 16 November 2013 were analysed with STRAT2D. As described above, the backscatter data are smoothed equivalently to a running arithmetic average over $30 \mathrm{~min}$ and evaluated every $5 \mathrm{~min}$ resulting in 26691 profiles for each instrument. All data below $350 \mathrm{~m}$ were rejected for both instruments as the CHM15k suffers from incomplete overlap up to this height. This reduces the number of MLH detections to 9173 with most of the samples occurring during daytime.

The average agreement is good with a bias of $3.6 \mathrm{~m}$ but the overall root mean square error (RMSE) is with $500 \mathrm{~m}$ rather large. Figure 1 shows absolute and relative difference between MLH from the Vaisala CT25K and the Jenoptik CHM15k over the course of the day. MLH is mainly detected between 08:00 and 18:00 UTC and the median differences closely follow the zero line over this period. Absolute differences show a strongly skewed distribution with maximum values larger than $1 \mathrm{~km}$. The first (third) quartile ranges from minimum values around $-150 \mathrm{~m}(+25 \mathrm{~m})$ in the morning and evening hours to $-40 \mathrm{~m}(+150 \mathrm{~m})$ around noon. As they vary with the time of the day relative difference seem to be more adequate for an error estimate. For a fixed time of day the relative differences are - albeit symmetrical - not following a Gaussian distribution. Therefore, instead of a standard deviation we consider the 25 and $75 \%$ percentile for the description of the uncertainty in the derived aerosol mixing-layer height $\mathrm{MLH}_{\text {aero }}$. Over the course of the day these percentiles are relatively constant and correspond to a relative accuracy of $\pm 5 \%$ (Fig. 1).

\subsection{Wind lidar}

Vertical wind speed is measured with a HALO Photonics Streamline wind lidar (Pearson and Collier, 1999; Pearson et al., 2010; Newsom, 2012). It is a coherent Doppler lidar that uses heterodyne detection to measure the Doppler shift of backscattered light. The instrument is based on a nearinfrared lidar system operating at a wavelength of $1.5 \mu \mathrm{m}$. The average pulse energy of $100 \mu \mathrm{J}$ is larger than the one of the aerosol lidars used in this study as the Doppler retrieval needs more photons to yield reliable results. Laser pulses are emitted at a frequency of $15 \mathrm{kHz}$ and averaged every second. Processing of these data takes some time resulting in a temporal resolution of $1.67 \mathrm{~s}$. In its current setup, the maximum range is $8 \mathrm{~km}$ but the actual range is limited to areas with sufficient occurrence of aerosol. The spatial resolution along the beam is set to $30 \mathrm{~m}$. Largest and smallest resolvable speed are 19.2 and $0.038 \mathrm{~ms}^{-1}$, respectively. The output consists of wind speed along the beam, backscatter coefficient and SNR from the heterodyne detection. The instrument is equipped with a scanner to point its beam in any direction of the upper hemisphere. In its current setup, it performs several different scan patterns to infer profiles of horizontal wind speed and its spatial distribution. These scans sum up to $12 \mathrm{~min}$ per hour. During the remaining $48 \mathrm{~min}$ per hour the wind lidar points vertically and measures profiles of vertical velocity.

Unreliable Doppler velocities are filtered by a SNR threshold of $\mathrm{SNR}_{\mathrm{ts}}=-18.2 \mathrm{~dB}$ derived from long-term noise characteristics. This value is somewhat larger than the threshold of $-20 \mathrm{~dB}$ used by Barlow et al. (2011) based on the considerations of Rye and Hardesty (1993). For the instrument used in this study, the value $\mathrm{SNR}_{\mathrm{ts}}$ indicates the SNR range below which the Doppler velocity consists only of white noise. It depends on the setup of the instrument, mainly the number of averages, and it differs from instrument to instrument but is relatively constant in space and time.

\subsubsection{MLH from vertical wind}

From the filtered time series of the vertical velocity, the standard deviation $\sigma_{w}$ is calculated every $5 \mathrm{~min}$ from the data of the surrounding $\pm 15 \mathrm{~min}$ interval. This standard deviation is corrected for instrumental noise following the technique described by Lenschow et al. (2000). Most of the time the correction is less than a few $\mathrm{cm} \mathrm{s}^{-1}$ or a few percent of $\sigma_{w}$. The average interval of $30 \mathrm{~min}$ is motivated by the consideration that a convective plume with an average ascent speed of $1 \mathrm{~ms}^{-1}$ needs about $16 \mathrm{~min}$ to travel through a mixing layer of $1 \mathrm{~km}$ height. The average interval is thus about twice the life time of such a plume and also typical for the derivation of turbulent fluxes from eddy covariance stations.

As shown by Taylor $(1922,1935)$ the vertical size of a plume growing due to homogeneous turbulent movement is proportional to $\sigma_{w}$. We thus use $\sigma_{w}$ as an indicator for vertical mixing. The MLH is determined as the first height 

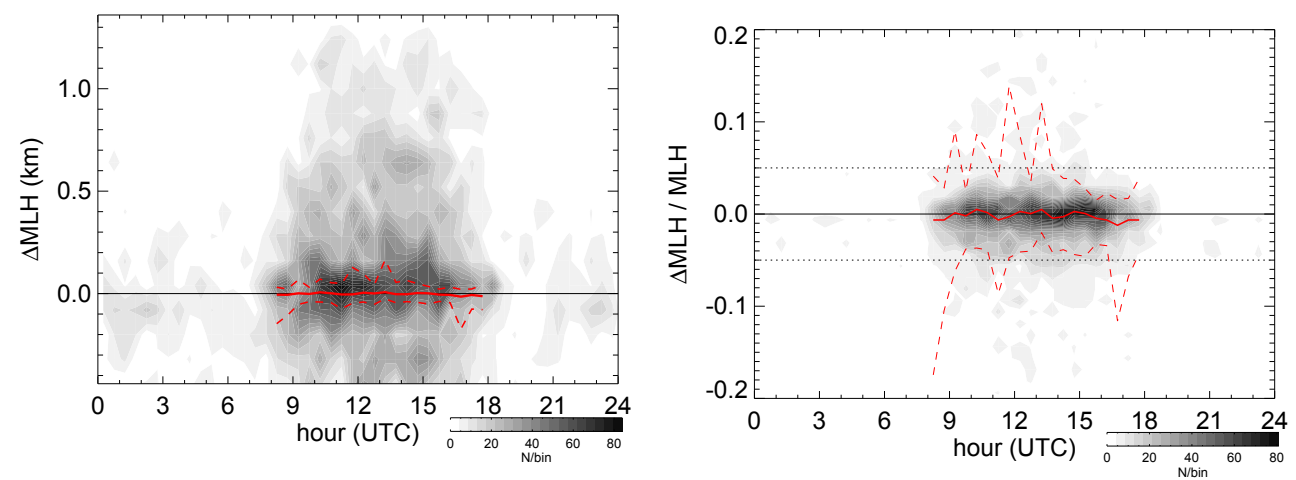

Figure 1. Absolute difference $\Delta \mathrm{MLH}=\mathrm{MLH}_{\mathrm{CT} 25 \mathrm{~K}}-\mathrm{MLH}_{\mathrm{CHM} 15 \mathrm{k}}$ (left) and relative difference $\Delta \mathrm{MLH} / \mathrm{MLH}_{\mathrm{CHM} 15 \mathrm{k}}$ (right) of retrieved $\mathrm{MLH}_{\text {aero }}$ from Vaisala CT25K and Jenoptik CHM15k as function of time of the day for the period 16 August-16 November 2013. Shading shows frequency of occurrence for bin sizes of $30 \mathrm{~min}$ and $120 \mathrm{~m}$ for absolute and $0.0125(1.25 \%)$ for relative MLH difference respectively. Red lines are the 25 and $75 \%$ percentile (dashed) and the median (solid) of half hour intervals, respectively. For the analysis 9173 data points were used. During half hour intervals when less than $20 \%$ of the data were available (see text) median and quartiles are not displayed. Dotted lines mark \pm 0.05 chosen as the average error for the $\mathrm{MLH}_{\text {aero }}$ estimate.
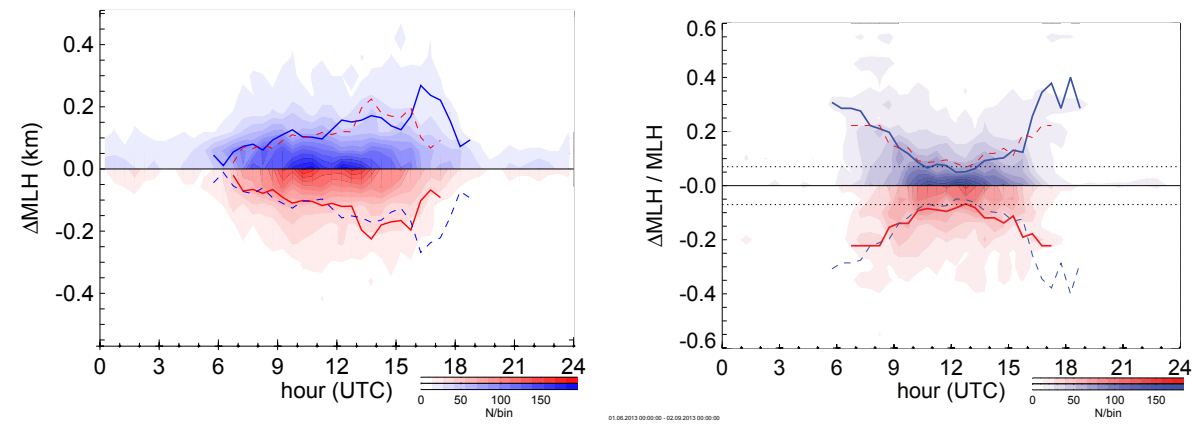

Figure 2. Absolute change $\triangle \mathrm{MLH}=\mathrm{MLH}_{ \pm}-\mathrm{MLH}_{0.4}$ (left) and relative change $\triangle \mathrm{MLH} / \mathrm{MLH}_{0.4}$ (right) of retrieved $\mathrm{MLH}_{ \pm}$for $\sigma_{w \mathrm{ts}}=(0.4 \pm 0.1) \mathrm{ms}^{-1}$ as a function of time of the day. Shading gives the histogram for single retrievals with $\sigma_{w \mathrm{ts}}$ increased (red) and decreased (blue). Bin size is $30 \mathrm{~min}, 60 \mathrm{~m}$ absolute and 0.05 (5\%) relative MLH change. Solid lines are half hour medians for increase (red) and decrease (blue) of $\sigma_{w \text { ts }}$, respectively. Dashed lines are medians mirrored at zero. A total of 8667 (11218) records have been used for the upper (lower) histograms. During daytime there are on average 440 out of 540 points per half hour interval. Medians are not shown for times when less than $20 \%$ of the original data gave an estimate. Horizontal black dotted lines indicate the $\pm 7 \%$ change derived from the $\sigma_{w}$ profile of Lenschow et al. (1980).

where $\sigma_{w}$ falls below a threshold $\sigma_{w \mathrm{ts}}$. Different thresholds have been used by Tucker et al. (2009) $\left(\sigma_{w \text { ts }}=0.20\right.$ and $\left.0.17 \mathrm{~ms}^{-1}\right)$, Pearson et al. (2010) $\left(0.30 \mathrm{~ms}^{-1}\right)$, Barlow et al. (2011) $\left(0.32 \mathrm{~ms}^{-1}\right)$ and Träumner et al. (2011) $\left(0.40 \mathrm{~ms}^{-1}\right)$. In order to derive a sensible $\sigma_{w \text { ts }}$ we make use of the semitheoretical profile of Lenschow et al. (1980). This profile is originally based on a handful of airplane measurements but has been recently confirmed with Doppler lidar measurements and LES simulations (Lenschow et al., 2012). We assume a typical convective velocity scale of $w_{\star}=1.5 \mathrm{~ms}^{-1}$ and arrive at $\sigma_{w \mathrm{ts}}=0.4 \mathrm{~ms}^{-1}$ (see Appendix B and Träumner, 2010). However, in reality $w_{\star}$ is time dependent and the Lenschow et al. (1980) profile is only valid for a developed convective boundary layer. The choice of a threshold method is of course somewhat unsatisfactory as it makes the retrieval dependent on this value and will be investigated in more detail below.

\subsubsection{Threshold sensitivity}

To investigate the sensitivity of the MLH derived from Doppler lidar to the threshold in $\sigma_{w \text { ts }}$ a 3-month period from June to August 2013 was selected and $\sigma_{w \text { ts }}$ increased and decreased by $25 \%$ to 0.5 and $0.3 \mathrm{~ms}^{-1}$, respectively. Times when the whole $\sigma_{w}$ profile remained below the threshold were excluded; that mainly concerned night-time data. The histograms (Fig. 2) for the absolute and relative MLH changes due the increase/decrease of $\sigma_{w t s}$ show a strong cluster at zero, i.e. in these cases the value of the threshold does not play a role. Nevertheless, the medians are non-zero and absolute differences in MLH average to $\pm 100 \mathrm{~m}$ with a more or less linear increase during the day from $\pm 50 \mathrm{~m}$ 

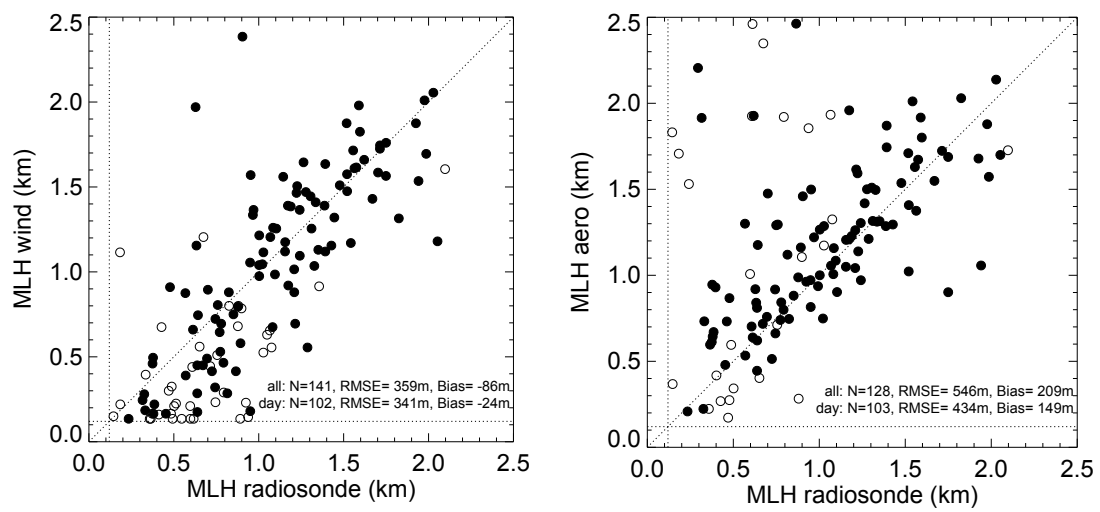

Figure 3. $\mathrm{MLH}_{\text {wind }}$ (left) and $\mathrm{MLH}_{\text {aero }}$ (right) versus $\mathrm{MLH}_{\text {sonde }}$ derived from HOPE data during April and Mach 2013. Filled symbols mark daytime (08:00-16:00 UTC) and open symbols night-time values.

(07:00 UTC) to $\pm 150 \mathrm{~m}$ (16:00 UTC). It should be noted that both medians lie symmetrically to zero indicating that the average $\sigma_{w}$ shows a linear decrease in this region of the ML.

Figure 2 reveals that best agreement in terms of relative error occurs between 10:00 and 15:00 UTC, i.e. the time frame in which a well-developed convective boundary layer is most likely. Here, the median of the relative differences is quite low and amounts to around $7 \%$. This is the same value as when using the Lenschow et al. (1980) profile that relates a change in height of $\pm 7 \%$ to a change in $\sigma_{w}$ by $\mp 25 \%$ (see Appendix B). In the morning and afternoon hours the relative difference increases to $\pm 30 \%$. This indicates that the Lenschow et al. (1980) profile is only valid around noon in the fully developed convective ML. In the morning and afternoon hours, the observed $\sigma_{w}$ profiles show a slower decrease with height and consequently the derived MLH depends more strongly on the choice of the threshold. We therefore consider $\pm 15 \%$ as error estimate for $\mathrm{MLH}_{\text {wind }}$.

\subsection{Comparison to radiosonde}

To evaluate the remotely sensed MLH retrievals, they are compared to MLHs derived from radio soundings. JOYCE was one of the three central sites of HOPE (High Definition Clouds and Precipitation for advancing Climate Prediction $\left(\mathrm{HD}(\mathrm{CP})^{2}\right)$ Observational Prototype Experiment, see http: //www.hdcp2.eu/). Two to five radiosondes were launched per day from a site $3.8 \mathrm{~km}$ to the southeast of JOYCE during the 2 month period April-May 2013. From this data set 141 profiles have been used for the comparison. The MLH retrieval from the radiosondes $\left(\mathrm{MLH}_{\text {sonde }}\right)$ was done with the bulk Richardson number method which is, according to Seibert et al. (2000), the best when also mechanically driven mixing should be detected. This method is based on the assumption that an air parcel (or plume) rising from the surface preserves its properties until it reaches a level where it is not buoyant any more and it is destroyed by the wind shear. This level is identified with the critical Richardson number and is typically slightly above the level of neutral buoyancy. Prior to the retrieval, profiles were smoothed with a five-point gliding average which is equivalent to about $50 \mathrm{~m}$. The reference level was chosen to be $60 \mathrm{~m}$ in order to avoid effects due to the local micrometeorology. For the critical Richardson number a value of 0.20 was used. $\mathrm{MLH}_{\text {wind }}$ and $\mathrm{MLH}_{\text {aero }}$ were determined from the $30 \mathrm{~min}$ average around the time when the sonde was in the middle of the mixing layer. MLH values below $120 \mathrm{~m}$ where rejected as the wind lidar is not sensitive below.

During days with frequent soundings the diurnal course of $\mathrm{MLH}_{\text {wind }}$ and $\mathrm{MLH}_{\text {sonde }}$ show in general good agreement even during some cases at night when large wind speeds induced shear driven mixing. The scatter plot of $\mathrm{MLH}_{\text {sonde }}$ versus $\mathrm{MLH}_{\text {wind }}$ (Fig. 3) shows, apart from some outliers, differences of less than $\pm 500 \mathrm{~m}$. Numerical analysis gives a bias of $-86 \mathrm{~m}$ and a RMSE of $359 \mathrm{~m}$ which is better than the values for $\mathrm{MLH}_{\mathrm{aero}}(209 \mathrm{~m}$ and $546 \mathrm{~m}$ respectively), or what is typically found when comparing any aerosol-based retrieval with radio soundings (see e.g. Korhonen et al., 2014; Luo et al., 2014; Haeffelin et al., 2012; Hennemuth and Lammert, 2006). Note that there are some night-time values with especially $\mathrm{MLH}_{\text {aero }}$ larger than $\mathrm{MLH}_{\text {sonde }}$ when the aerosol-based algorithm detects the top of (or aerosol layers within) the RL while $\mathrm{MLH}_{\text {wind }}$ shows good agreement. Omitting these points from the analysis still gives worse results for $\mathrm{MLH}_{\text {aero }}$. In summary it can be said that $\mathrm{MLH}_{\text {wind }}$ compares much better to the radiosonde-based MLH than $\mathrm{MLH}_{\text {aero }}$.

\section{Results}

In this section we first compare the performance of MLH retrievals derived from backscatter and vertical velocity profiles by means of a case study (Sect. 3.1) to illustrate the principal differences between both methods. We then proceed to a statistical analysis of a 1-year data set (Sect. 3.2) 

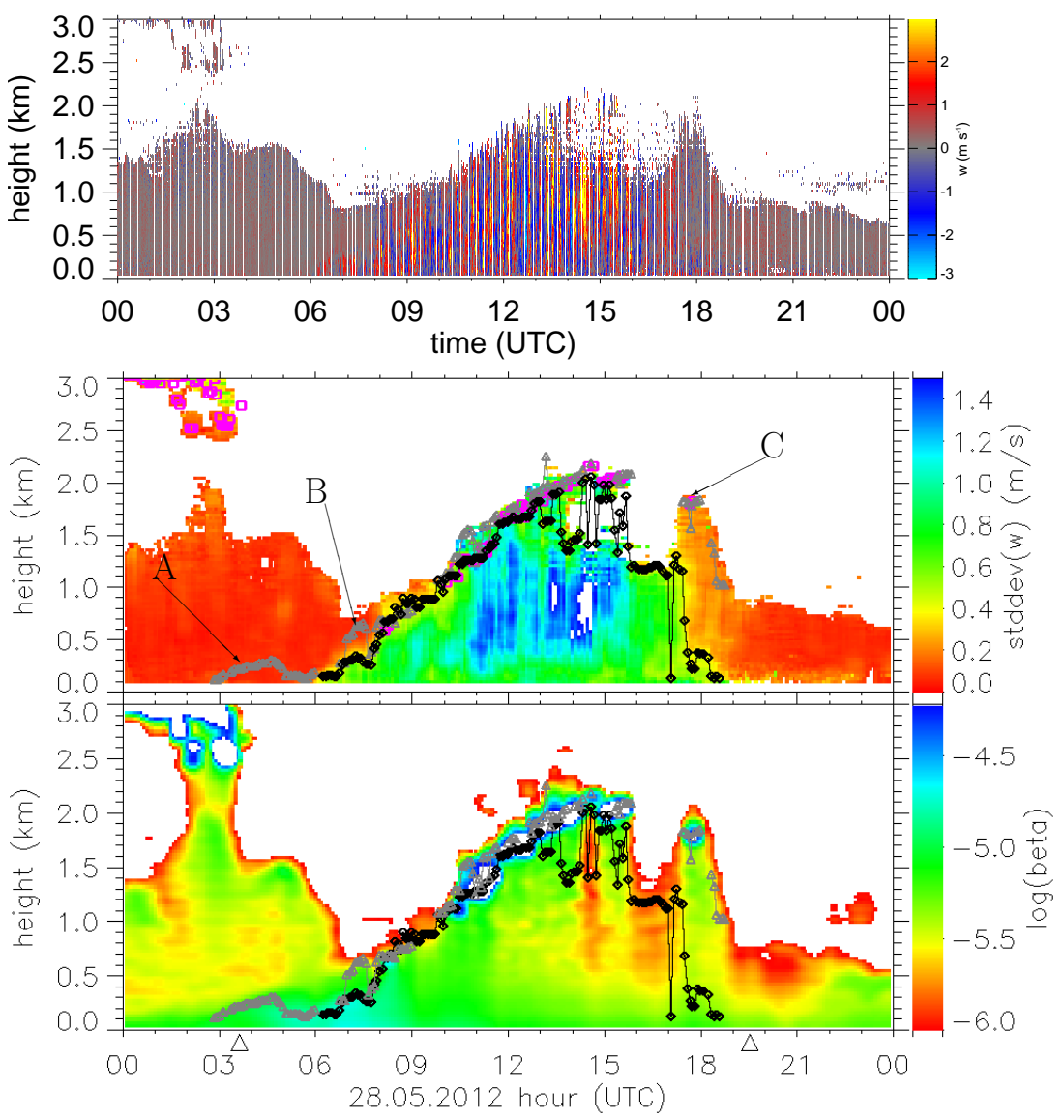

Figure 4. Time-height sections of vertical velocity (top), its standard deviation (stddev, mid panel) and aerosol backscatter coefficient (beta, bottom panel) on 28 May 2012. MLH retrieved from wind lidar (solid black with diamonds) and from ceilometer (solid grey with triangles). Magenta squares indicate cloud base heights as determined by the ceilometer. Triangles at the abscissa mark sunrise and sunset. Letters A, B and $\mathrm{C}$ refer to descriptions in the text. Temporal resolution of the vertical velocity plot is $1 \mathrm{~min}$.

and finally investigate mixing-layer characteristics such as maximum MLH and average growth rate (Sect. 3.3).

\subsection{Case study}

To investigate the performance of the aerosol-based STRAT2D compared to the wind-based MLH retrieval, a fair weather spring day (JOYCE, 28 May 2012) with a classical "textbook" boundary layer development is analysed (Fig. 4). Between midnight and 08:00 UTC the residual layer is visible as a region with low values of the standard deviation of vertical velocity $\left(\sigma_{w}<0.20 \mathrm{~ms}^{-1}\right)$ up to approx. $1.5 \mathrm{~km}$. Convection begins to develop around 06:00 UTC, i.e. $2.5 \mathrm{~h}$ after sunrise, as indicated by enhanced $\sigma_{w}$ close to the surface. The MLH steadily increases and reaches the maximum RL height at around 09:00 UTC. At 14:00 UTC the ML reaches its maximum height at about $2.1 \mathrm{~km}$ and begins to stagnate. Additionally, starting from 10:30 UTC, cumulus clouds start to develop at the top of the ML visible by the high backscatter and subsequent extinction of the signal above in Fig. 4. Turbulent mixing begins to decay at 16:00 UTC and collapses almost completely throughout the whole ML at 17:30 UTC, 2 hours before sunset.

Most of the time, both MLH retrievals show good agreement. However, some features revealing typical problems of deriving MLH from backscatter profiles can also be observed (refer to arrows with letters in Fig. 4). In situation A, the height of the nocturnal boundary layer is interpreted as MLH, although $\sigma_{w}$ values are well below $0.1 \mathrm{~ms}^{-1}$. Around 07:00 UTC (situation B), aerosol layers within the RL or at its top around $700 \mathrm{~m}$ are erroneously retrieved as MLH, although significant mixing is only taking place below $300 \mathrm{~m}$. Finally in situation C (afternoon, starting at 17:00 UTC), the detection of the breakdown of the ML is delayed due to remaining aerosol particles aloft.

In order to gain further insight into the differences between the aerosol- and wind-based MLH retrievals, the thermal structure of the ABL is considered (Fig. 5). Potential temperature profiles are derived from the microwave radiometer HATPRO (Rose et al., 2005) that uses measurements at six different elevation angles to retrieve the vertical profile in 


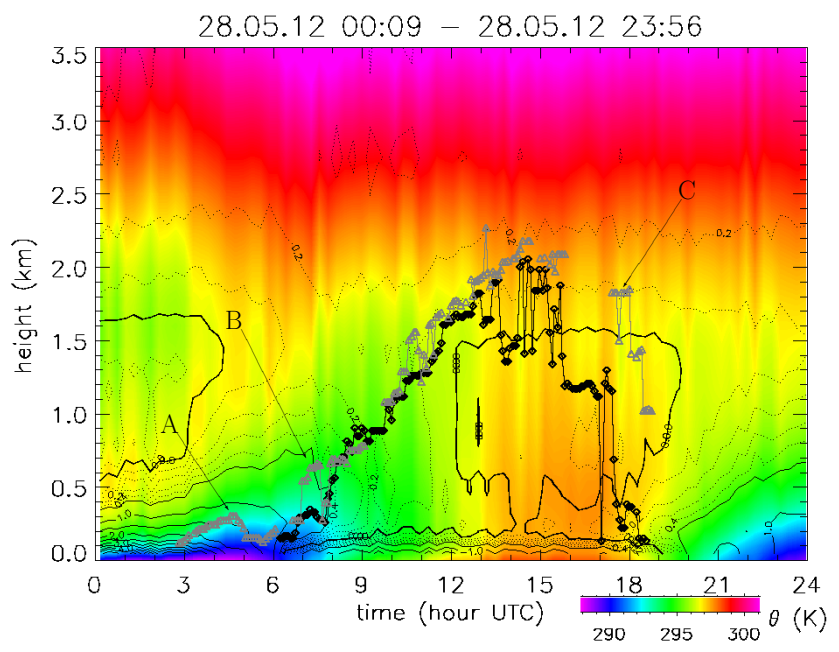

Figure 5. Time-height section of potential temperature from HATPRO (colour shading). Black line with diamonds shows ML from wind, grey line with triangle ML from aerosol. Solid isolines show the vertical potential temperature gradient in steps of $0.5 \mathrm{~K} / 100 \mathrm{~m}$ (solid), dotted lines in steps of $0.1 \mathrm{~K} / 100 \mathrm{~m}$ between $-0.9 \mathrm{~K} / 100 \mathrm{~m}$ to $+0.9 \mathrm{~K} / 100 \mathrm{~m}$. The thick isoline marks neutral stratification $(0 \mathrm{~K} / 100 \mathrm{~m})$. Letters A, B and C refer to descriptions in the text.

the lowest hundred metres of the ABL very accurately with a high resolution of decameters (Löhnert and Meier, 2012). Higher up in the ABL, spatial resolution decreases rapidly, such that the inversion at the top of the boundary layer is usually not resolved.

Potential temperature during night clearly shows the stably stratified and cold nocturnal boundary layer (NBL) with temperatures down to $289 \mathrm{~K}$ (04:30 UTC) and gradients of more than $+4 \mathrm{~K} / 100 \mathrm{~m}$ (01:00-03:00 UTC) close to the surface (Fig. 5). The region with pronounced stable stratification grows until 06:00 UTC in the morning (2.5 $\mathrm{h}$ after sunrise) when stratification close to the surface quickly transforms from stable to unstable.

During the time span of the lowest temperatures close to the surface, $\mathrm{MLH}_{\text {aero }}$ increases from $120 \mathrm{~m}$ at 03:00 UTC to around $300 \mathrm{~m}$ at 04:30 UTC. However, vertical mixing is very unlikely, as stratification at this time is stable with a strong positive potential temperature gradient. In agreement with this, the Doppler lidar did not detect any significant vertical air movement and thus no MLH was assigned (arrow A in Fig. 4). However, $\beta$ profiles show a region with a significant vertical gradient leading to the detection of a deepening ML between 03:00 and 05:00 UTC. Most probably this development was connected to the dissipation of thin mid-level liquid water clouds (base $>2.5 \mathrm{~km}$, top $<3.2 \mathrm{~km}$ as derived from the cloud radar at JOYCE) at 03:00 UTC followed by increased radiative cooling, decreasing temperature (Fig. 5) and increasing relative humidity in the lowest few $100 \mathrm{~m}$. This may have initiated hydrophilic aerosol growth in the stable NBL and consequently an increasing gradient in the backscatter profiles was interpreted as MLH.

Beginning at 06:00 UTC the ML grew into the NBL, dissolved it and further grew in the neutrally stratified RL. Between 07:00 and 08:00 UTC the aerosol-derived MLH shows higher values $(700 \mathrm{~m})$ than the wind-derived MLH $(250 \mathrm{~m}$, arrow B in Figs. 4 and 5). Stratification in this region was still stable and vertical wind as low as during the night. Aerosol backscatter below the wind-derived MLH showed enhanced values. Nevertheless, the gradient in $\beta$ at this height seems to be lower than gradients in the RL above or even at the top of the RL and these heights are consequently assigned as MLH. The most probable explanation for this behaviour is that with the breakup of the NBL temperature increases, relative humidity decreases and backscatter decreases as well. The backscatter gradient at the top of the ML becomes smaller than gradients in the RL above.

The third situation (arrow C in Figs. 4 and 5) illustrates that the aerosol-based STRAT-2D algorithm cannot follow the breakdown of the MLH around 17:45 UTC. Instead, the top of the aerosol layer, which at this time is the top of the $\mathrm{RL}$, is identified as the MLH. Unfortunately, it is not possible to analyse the temperature inversion at the top of the ABL due to low spatial resolution of the MWR data at these heights. However, Träumner et al. (2011) already noted that incorrect detection during MLH decay is due to the fact that the aerosol distribution in the ABL represents the history of the mixing processes, whereas the vertical wind shows the current status of vertical mixing.

\subsection{Average diurnal cycle}

After discussing typical issues concerning MLH detection from aerosol backscatter profiles in comparison to the more realistic retrievals from wind lidar in the section above, we now analyse the impacts of the different retrievals on the average diurnal cycle of the MLH. The analysis is carried out over the course of a full year (four seasons) of JOYCE observations between December 2011 and November 2012 (Fig. 6). The winter of the investigated period, especially December and January, were characterized by stormy but relative mild weather, whereas spring and autumn had less precipitation than average, increasing the chance for higher MLHs (Deutscher Wetterdienst, 2011 and 2012).

MLH values below $120 \mathrm{~m}$ are excluded as both retrievals fall back to values below if no MLH can be found, which was the case for about $50 \%$ of the data. Time series are synchronized and values are only accepted when both retrievals provide a value. When less than $20 \%$ of the original data remains, statistics are not evaluated, which mainly excludes the night-time values. Note that the analysis is carried out for all cases including cloudy (e.g. frontal passages and cumulus clouds) and clear-sky cases. On average the wind lidar could provide a valid MLH retrieval during $43 \%$ of all the times (including nights), whereas the MLH availability from 

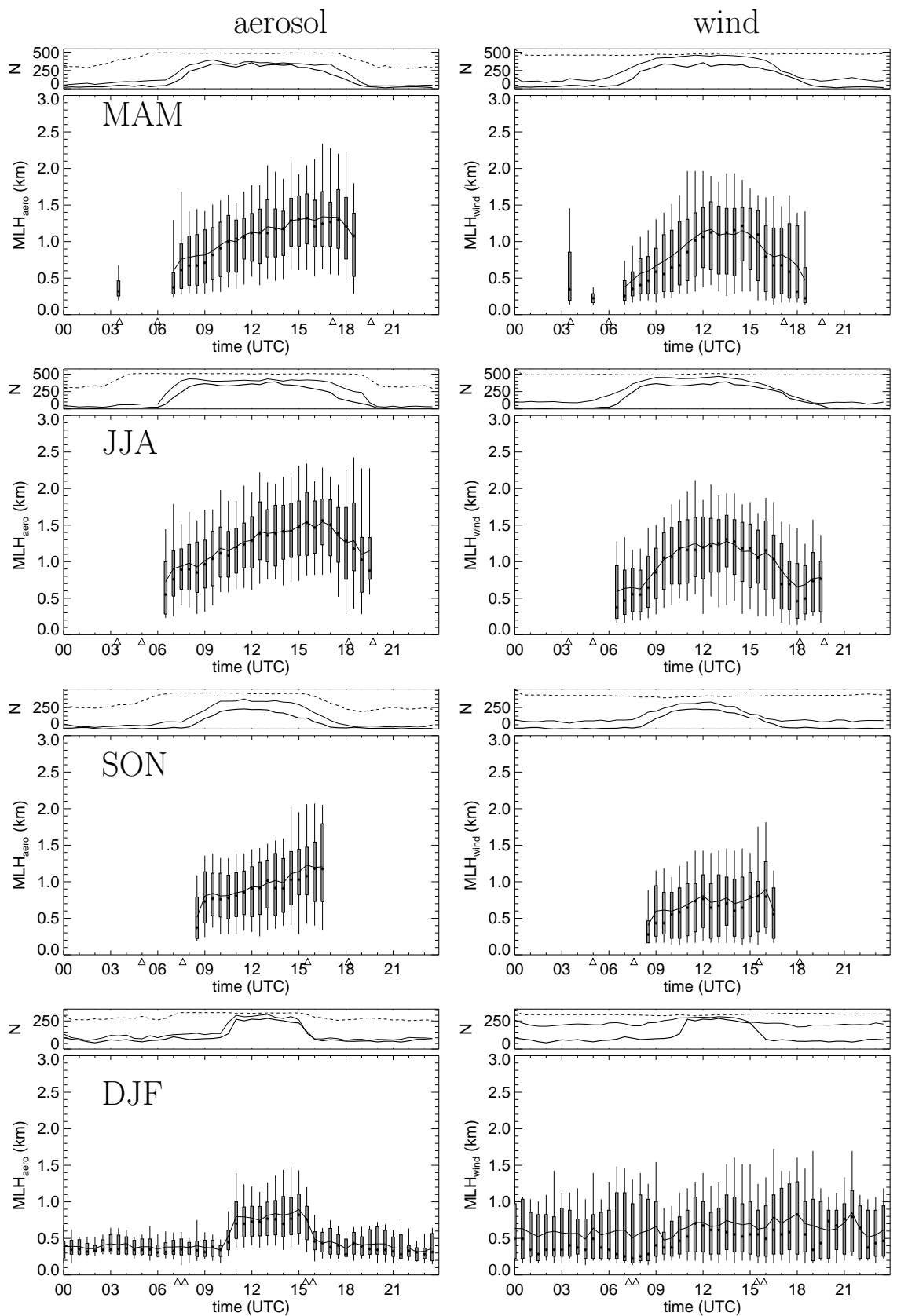

Figure 6. Average diurnal course (solid line) of MLH from aerosol (left panels) and vertical wind (right panels) for spring (MAM), summer (JJA), autumn (SON) and winter (DJF). Whiskers and boxes indicate 10, 25, 75 and $90 \%$ percentiles. The centre dot indicates the median. On top of every subplot the number of cases $N$ is shown before excluding any data (dashed line), after excluding data below $120 \mathrm{~m}$ (solid thin line) and after synchronizing with the other instrument (solid thick line). Triangles at the abscissa mark range of sunrise and sunset during the respective season.

the ceilometer was $40 \%$ (see Table 2). In general data availability from both instruments is similar (see also the number of cases in Fig. 6).

The MLH from both methods show an increase in the morning until noon in spring and summer (MAM and JJA in Fig. 6), which is in general agreement with the common knowledge of the development of a convective boundary layer (e.g. Stull, 1988). During spring (summer) the average $\mathrm{MLH}_{\text {wind }}$ begins to decrease 2 (resp. 3) hours before sunset. In contrast to this, $\mathrm{MLH}_{\text {aero }}$ remains longer at higher MLH values, decreasing in height with sunset (spring) or 2 hours before the earliest sunset (summer). This behaviour generalizes the difference between $\mathrm{MLH}_{\text {wind }}$ and $\mathrm{MLH}_{\text {aero }}$ already noted in situation $\mathrm{C}$ within the case study (Figs. 4 and 5). In 

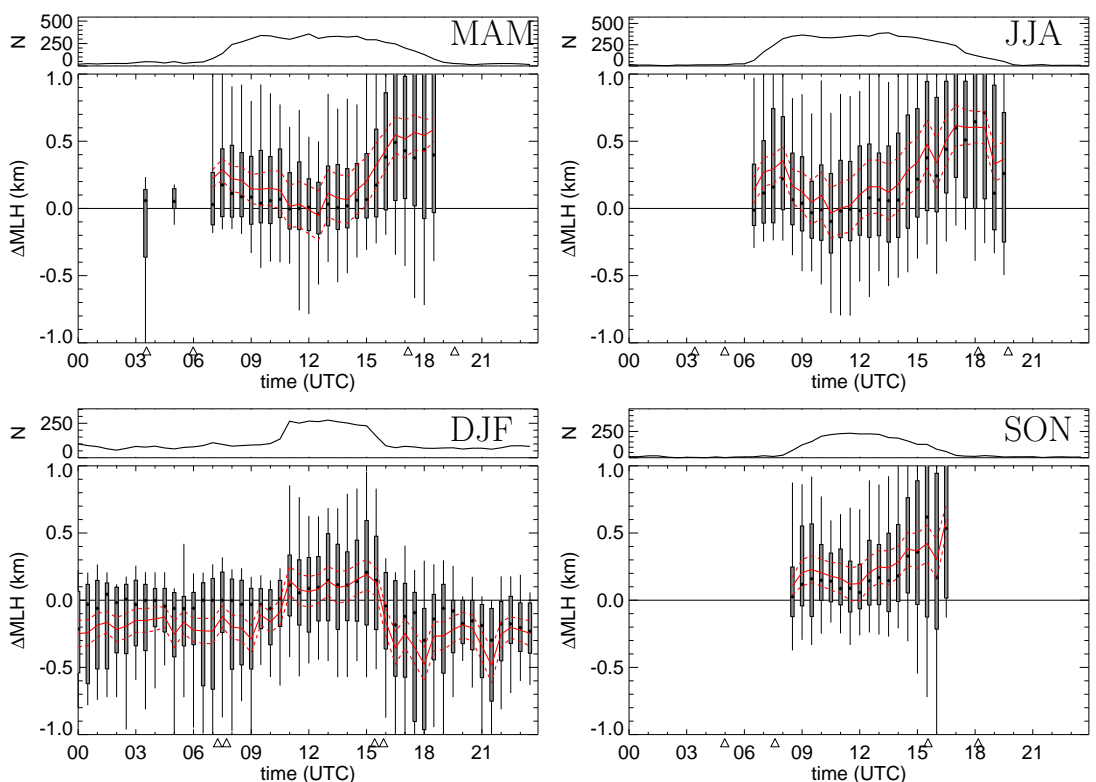

Figure 7. Difference $\triangle \mathrm{MLH}=\mathrm{MLH}_{\mathrm{aero}}-\mathrm{MLH}_{\text {wind }}$ for the four seasons. Whiskers and boxes indicate $10,25,75$ and $90 \%$ percentiles and dots indicate the median. Red lines indicate average (solid) and the error estimate based on the sensitivity studies in Sects. 2.1.4 and Sect. 2.2.2 (dashed). Triangles at the abscissa mark range of sunrise and sunset during the respective season.
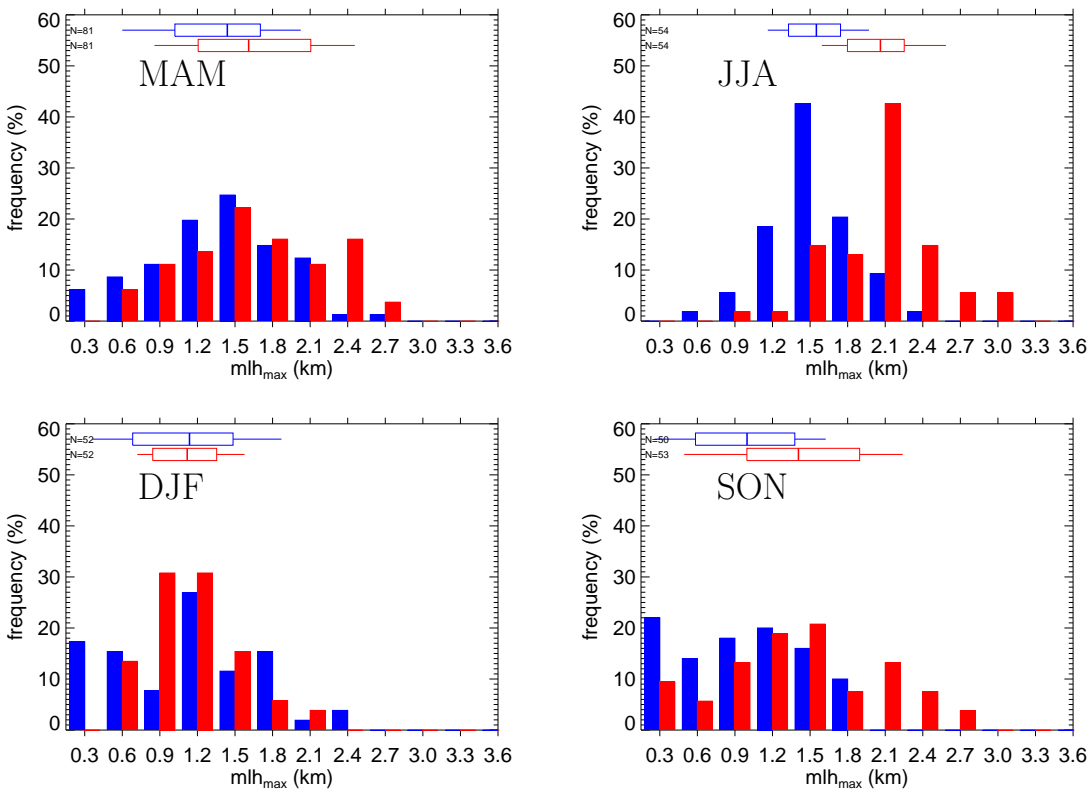

Figure 8. Frequency of occurrence of maximum MLH from wind lidar (blue) and ceilometer (red) for spring, summer, autumn and winter (clockwise from top left). Whisker boxes on top show 10, 25, 75 and $90 \%$ percentiles and the median.

the morning hours before noon, average $\mathrm{MLH}_{\mathrm{aero}}$ is in general larger and shows a smaller growth rate than $\mathrm{MLH}_{\text {wind }}$. This could be related to situations denoted as B in the case study above (Figs. 4 and 5). In winter (DJF), night-time values above the minimum ML are frequently retrieved by both methods. This is due to a rather large number of storm passages in the winter data set. The observed large nocturnal mixing-layer heights are thus not convectively driven, but caused by wind shear. Switching of the STRAT-2D algorithm between the day mode (beginning $3 \mathrm{~h}$ after sunrise) and the night mode (beginning with sunset) is in winter clearly visible as a sudden increase in $\mathrm{MLH}_{\text {aero }}$. In contrast, $\mathrm{MLH}_{\text {wind }}$ does not show a diurnal course and it can be concluded that 

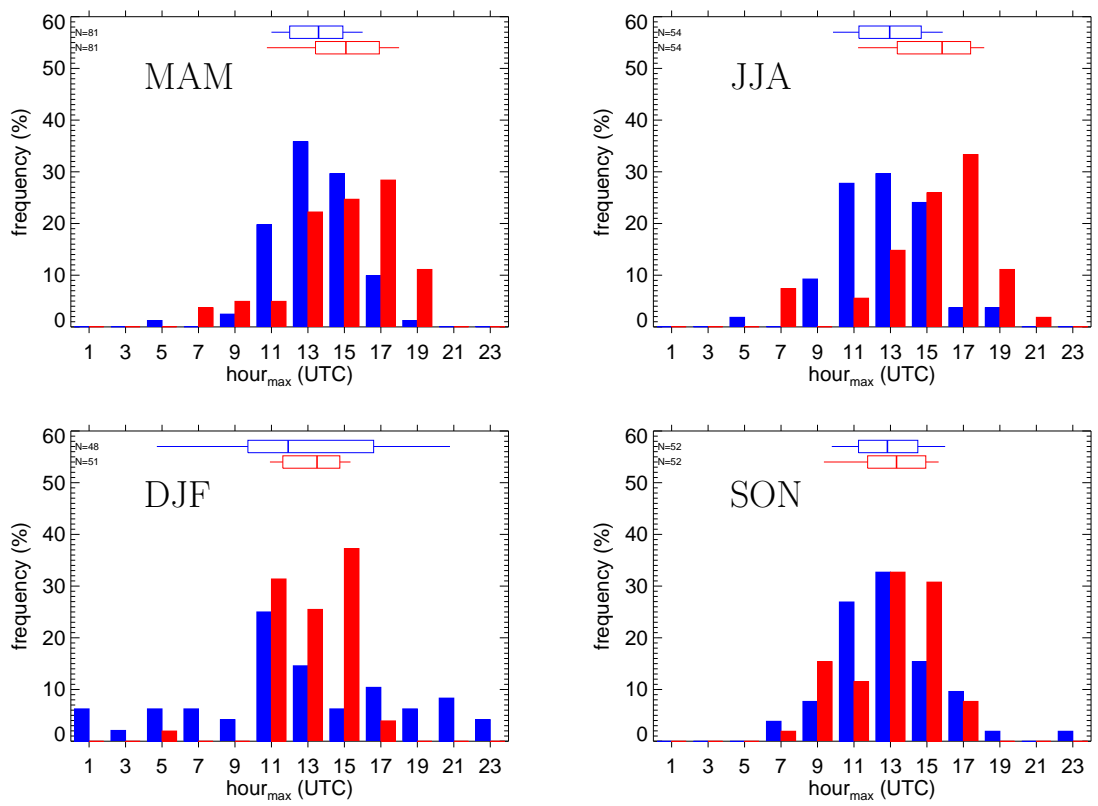

Figure 9. Frequency of occurrence of time of the day when maximum MLH is reached for wind lidar (blue) and ceilometer (red) derived MLH. Clockwise from top left: spring, summer, autumn and winter. Whisker boxes on top show 10, 25, 75 and $90 \%$ percentiles and the median.
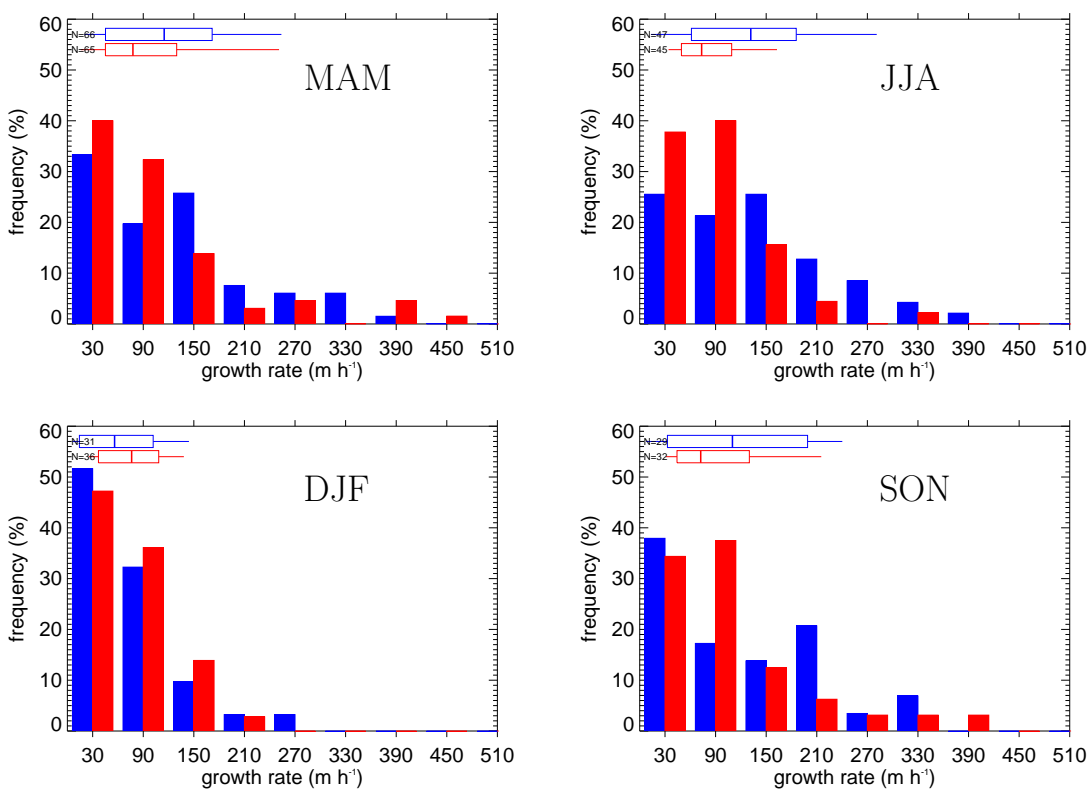

Figure 10. Frequency of occurrence of average growth rate of MLH between sunrise and time when $90 \%$ of $\mathrm{MLH}_{\text {max }}$ is reached. Clockwise from top left are shown spring, summer, autumn and winter. Whisker boxes on top show 10, 25, 75 and $90 \%$ percentiles and the median.

the switching of STRAT-2D between night and daytime is not working properly at least in winter time.

In general, the difference $\triangle \mathrm{MLH}=\mathrm{MLH}_{\mathrm{aero}}-\mathrm{MLH}_{\text {wind }}$ is positive for all seasons except for night-time in winter (Fig. 7). This is as expected, as the wind retrieval of a Doppler wind lidar depends on aerosol backscatter. They should be equal in the case of a fully developed ML above which only clean air of the free troposphere and thus no backscatter can be found. In the case of a developing ML, which grows into the RL, there might be aerosol above and $\mathrm{MLH}_{\text {aero }}$ could be larger than $\mathrm{MLH}_{\text {wind }}$. In contrast, the comparison by Pearson et al. (2010) showed $\mathrm{MLH}_{\text {wind }}$ to be larger than $\mathrm{MLH}_{\text {aero }}$ but as their measurements were taken in the tropics, humidity might have affected the aerosol particle 

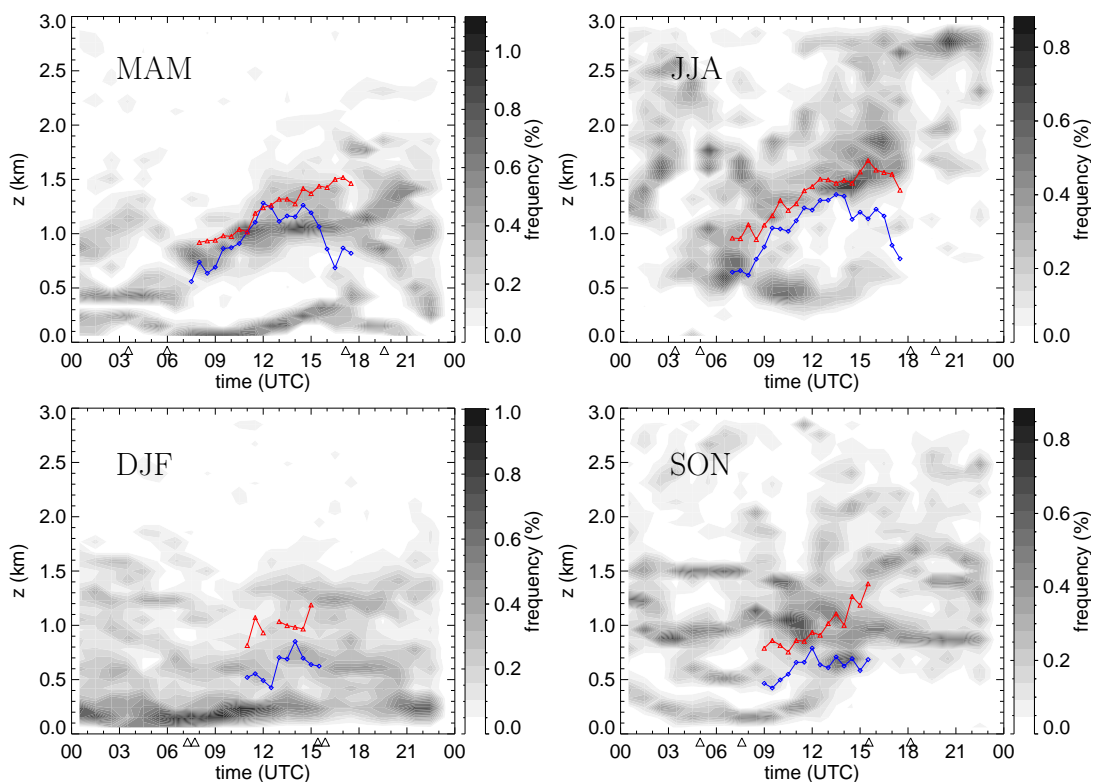

Figure 11. Frequency of occurrence of cloud bases (shading) and overlaid ML from ceilometer (red) and wind lidar (blue) with cloudy cases excluded. Bin size is $90 \mathrm{~m} \times 1 \mathrm{~h}$. Cloud base heights are excluded from half hour intervals when cloud coverage was larger than 4 octa.

Table 3. Seasonal medians of daily maximum MLH (max), time of maximum ( $\mathrm{h}_{\max }$ ) and growth rate (GR) of MLH for JOYCE, December 2011-November 2012.

\begin{tabular}{lcccc|cccc}
\hline & \multicolumn{4}{c}{ Wind } & \multicolumn{4}{c}{ Aerosol } \\
& MAM & JJA & SON & DJF & MAM & JJA & SON & DJF \\
\hline $\max (\mathrm{km})$ & 1.4 & 1.6 & 1.0 & 1.1 & 1.6 & 2.1 & 1.4 & 1.1 \\
$\mathrm{~h}_{\max }($ hour UTC) & 13.6 & 13.0 & 12.8 & 11.9 & 15.1 & 15.8 & 13.3 & 13.5 \\
GR $\left(\mathrm{m} \mathrm{h}^{-1}\right)$ & 115 & 131 & 109 & 56 & 78 & 73 & 72 & 76 \\
\hline
\end{tabular}

properties. From our study it is obvious that on average $\mathrm{MLH}_{\text {wind }} \leq \mathrm{MLH}_{\text {aero }}$ holds.

The spread of the differences between both MLHs, depicted by the 25 and $75 \%$ percentiles, is rather large with values up to $500 \mathrm{~m}$ (Fig. 7) but in the same order of magnitude as the differences found when comparing to radiosondes (see Sect. 2.3). The spread is largest in the afternoon and larger in summer than in spring and autumn. Considering the error estimate based on the sensitivity studies in Sects. 2.1.4 and Sect. 2.2.2 the differences are significant most of the time, particularly in the late afternoon in spring, summer and autumn (Fig. 7). As this difference cannot be removed by changing the threshold $\sigma_{w \text { ts }}$ within the large range investigated in Sect. 2.2.2 it must be concluded that $\mathrm{MLH}_{\text {aero }}$ is systematically overestimated.

In spring, summer and autumn, mean and median of $\triangle \mathrm{MLH}$ show the same behaviour: larger differences in the morning and afternoon hours and values closer to zero around noon. The overestimation of $\mathrm{MLH}_{\mathrm{aero}}$ is strongest in the morning and the late afternoon during these seasons. The largest differences occur in the late afternoon reaching average and median values of $600 \mathrm{~m}$ which is in the order of the
MLH itself at that time of the day. Similarly, in the morning, the difference in MLH is of the order of $300 \mathrm{~m}$. This pattern of MLH differences does not appear during winter (DJF) when convective conditions are rather rare.

Because the presented statistics include many different weather situations, the retrievals might be biased by other atmospheric phenomena such as precipitation, layers within stable stratification or clouds. As the classical definition of MLH development mostly applies during fair weather conditions, the analysis was repeated for cases where cloud cover by clouds below $3 \mathrm{~km}$ was below 4 octa. This removes frontal passages with periods of high cloud cover but also precipitation as it is connected to clouds. The number of cases is reduced by about $45 \%$ (summer and spring), $50 \%$ (autumn) and $70 \%$ (winter). However, except for winter the MLH statistics do not differ much from the results above: in winter, night-time cases are removed and during daytime the average MLH is growing, indicating that the statistics are more dominated by convective days. For the other seasons the average diurnal course remains similar with slightly larger differences between the two retrievals. 


\subsection{Mixing-layer characteristics}

The daily development of the ML can be characterized by three parameters: the maximum height $\left(\mathrm{MLH}_{\max }\right)$, the time when this height is reached (hour $r_{\max }$ ) and the rate at which the $\mathrm{ML}$ is growing in the morning hours (GR). As $\mathrm{MLH}_{\text {aero }}$ is larger than $\mathrm{MLH}_{\text {wind }}$ in the morning and late afternoon, we can expect that there will be systematic differences in the ML characteristics from the two instruments.

For the determination of the daily maximum of MLH, both data sets $\mathrm{MLH}_{\text {aero }}$ and $\mathrm{MLH}_{\text {wind }}$ are smoothed with a 1-hour gliding average to avoid outliers to be taken as the maximum. The growth rate is determined similar to Baars et al. (2008) and Korhonen et al. (2014) as the slope of a linear fit to the data between the first reported MLH after sunrise and the time when $90 \%$ of the maximum is reached. It is thus an average growth rate.

As for the half-hourly averages, the largest maximum MLHs are observed in summer and maxima are larger in spring than in autumn (Fig. 8 and Table 3). Winter values are rather high which is again related to the stormy winter with several days with shear-induced mixing. A comparison with $\mathrm{MLH}_{\text {wind }}$ reveals a systematic overestimation by the aerosol-based retrieval which is with $500 \mathrm{~m}$ largest in summer, smaller in spring $(200 \mathrm{~m})$ and autumn $(400 \mathrm{~m})$ and negligible only in winter. Medians of the seasonal maximum $\mathrm{MLH}_{\text {aero }}$ are by about $300 \mathrm{~m}$ larger than those values from Baars et al. (2008) for Leipzig, a central European site, whereas $\mathrm{MLH}_{\text {wind }}$ agrees very well for spring and autumn and even the difference in summer is lower than the uncertainty due to day-to-day variability. Values are also comparable to those found by Granados-Muñoz et al. (2012) at a site in southern Spain. They are larger than those reported by Chen et al. (2001) for a city in Japan which is probably due to the more moist climate and thus a lower surface sensible heat flux. As one could expect, they are lower than those found by Korhonen et al. (2014) in South Africa at a lower latitude in a drier climate.

The median of the time when the maximum $\mathrm{MLH}_{\text {wind }}$ is reached is for all seasons, except winter, around 13:00 UTC i.e. 1.3 hours after local noon (Fig. 9). The quartiles indicate that, except in winter, more than half of the cases are within \pm 2 hours of this time while the time of maximum $\mathrm{MLH}_{\text {aero }}$ occurs in spring and summer by about 2.5 hours later than that of $\mathrm{MLH}_{\mathrm{wind}}$. In winter, shear-induced mixing leads to MLH maxima during night which are only detected by $\mathrm{MLH}_{\text {wind }}$. Both results, the larger and the later maximum of $\mathrm{MLH}_{\mathrm{aero}}$, can be explained by the incapability of the aerosol-based retrieval to capture the termination of convection, i.e. when $\mathrm{MLH}_{\text {aero }}$ shows a still growing ML, while the vertical wind indicates no more mixing. Nevertheless, it remains unclear why $\mathrm{MLH}_{\text {aero }}$ is growing although the vertical wind indicates no mixing connected to the surface. A possible reason could be shear-induced mixing at the top of the residual layer which would dilute aerosol into the free troposphere and thus lift the region with the most significant gradient.

Mean growth rates of $\mathrm{MLH}_{\text {wind }}$ are largest in summer with $50 \%$ of the days showing values larger than $131 \mathrm{~m} \mathrm{~h}^{-1}$ (Fig. 10). Growth rates in spring are larger than those in autumn which is similar to the observed larger maxima in spring compared to autumn. In winter, growth rates are in general smaller and often lie below $120 \mathrm{~m} \mathrm{~h}^{-1}$. The distribution is during all seasons positively skewed with largest values around $390 \mathrm{~m} \mathrm{~h}^{-1}$. The 1-year statistics derived by Baars et al. (2008) and Korhonen et al. (2014) are both also skewed but show larger values (up to $600 \mathrm{~m} \mathrm{~h}^{-1}$ ) and also lesser values below $100 \mathrm{~m} \mathrm{~h}^{-1}$. This might be related to the fact that both studies are restricted to cases with no boundary layer clouds and thus higher insolation, higher convective activity and thus less small growth rates. The fact that they had to restrict their analysis to times when the MLH reaches the height with sufficient lidar overlap, i.e. $300 \mathrm{~m}$, may also play a role: this restriction excludes the morning hours of slow MLH growth when the NBL is dissolved. The

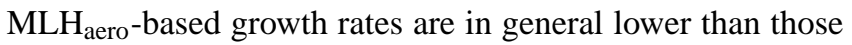
of $\mathrm{MLH}_{\text {wind }}$ with the median between $37 \mathrm{~m} \mathrm{~h}^{-1}$ (spring and autumn) and $58 \mathrm{~m} \mathrm{~h}^{-1}$ lower (see Table 3). This behaviour can be explained by the tendency of the aerosol-based retrieval to detect the top of, or layers within, the residual layer, especially in the morning hours. This results in larger morning MLHs and thus in lower average growth rates.

\subsection{Connection of ML to clouds}

Cumulus clouds are directly connected to the atmospheric boundary layer as they are the convective plumes which become visible due to condensation. To investigate this further we compare here cloud bases as detected by the ceilometer with the MLH found by the two methods. We use the data set with cloud cover below $3 \mathrm{~km}$ lower than 4 octa. Although this does not fully guarantee that the observed clouds are cumulus clouds, we regard it as a first attempt to restrict to this cloud class.

Figure 11 shows a 2-D histogram of cloud base heights $(\mathrm{CBH})$ with the average MLHs from aerosol- and wind-based retrieval overlaid. Cloud bases are those reported every $15 \mathrm{~s}$ by the Vaisala ceilometer. The cloud base statistic is similar to what Brümmer et al. (2012) found in a 7-year statistic from a site near Hamburg about $380 \mathrm{~km}$ to the northeast of JOYCE under similar climatic conditions (Fig. 18 in Brümmer et al., 2012). A similar pattern can also be found in the Climate Modeling Best Estimate data set derived from a continental site (CMBE, Fig. 3a in Xie et al., 2010).

In the presented study we can show that in spring and summer CBHs are frequently at the same height as the average MLH. They follow the diurnal course of the MLH from the morning until afternoon. In autumn and winter this distinct connection between MLH and CBH is not visible. Instead, in autumn there is a cluster of cloud occurrence around $1 \mathrm{~km}$ 
Table 4. Comparison of the capabilities of the MLH retrievals in different situations. AL, aerosol layer; ML, mixing layer; NBL, nocturnal boundary layer; RL, residual layer.

\begin{tabular}{lclcl}
\hline Situation & \multicolumn{2}{c}{ Ceilometer } & \multicolumn{1}{c}{ Wind lidar } \\
\hline Night & -- & detects ALs, NBL or top of RL & + & intermittent turbulence? \\
Growing ML & $\circ$ & no gradient between ML and RL & ++ & clear difference between ML and RL \\
Fully developed ML & ++ & top of ML coincides with top of AL & ++ & strong turbulence over whole ML \\
Evening decay & - & sticks to top of aerosol layer & + & sees decaying mixing \\
\hline
\end{tabular}

which might be related to dissolving stratus clouds. In winter highest frequencies for cloud bases are in the lowest few hundred metres, which might be related to fog.

The strong connection between MLH and CBH in spring and summer coincides with the general experience that the base of cumulus clouds is located always more or less at the top of the boundary layer but never significantly below and of course never above (see e.g. studies on shallow trade wind cumulus - Riehl et al., 1951; Augstein et al., 1974). The mechanism can be described as follows: the ML grows until it reaches the cumulus condensation level (CCL) and cumulus clouds form. Incident solar radiation at the surface is reduced, convection becomes weaker and ML growth is reduced. Warming and drying of the ML lifts the CCL and cloud cover is reduced. Incident solar radiation and thus convection increases and again influences the cloud cover. Several studies used large eddy simulation (LES) to understand the role of the different fluxes in the mass and heat budget of the cumulus topped ABL (see e.g. Brown et al., 2002). Others investigate mass flux schemes suitable for climate models (e.g. Neggers et al., 2004). All these model studies show that there is a strong coupling between CCL and MLH.

As the determination of $\mathrm{CBH}$ is much simpler than the determination of MLH it could be used as a good proxy for MLH. Nevertheless, it is necessary to ensure that the observed clouds are convective, e.g. by investigating the surface sensible heat flux $H_{s}$. This could be done in a multi-sensor approach as proposed e.g. in the boundary layer classification by Harvey et al. (2013), or in a simpler way by checking in situations with sufficiently large $H_{s}$, whether $\mathrm{MLH}_{\text {aero }}$ lies close to $\mathrm{CBH}$.

\section{Summary and conclusions}

We analysed and compared 1 year of MLHs derived from (i) aerosol backscatter and (ii) standard deviation of the vertical wind speed. To our knowledge this is the first longterm evaluation of vertical wind derived MLH. For (i) we used backscatter data from a Vaisala CT25K ceilometer and the STRAT-2D algorithm with its core based on an edge detection algorithm (Sect. 2.1). For (ii) we used vertical wind speed data from a HALO Photonics streamline wind lidar and a threshold algorithm (Sect. 2.2). The basic idea is that the vertical velocity is a direct measure of the turbulent mix- ing, while in contrast the backscatter profile is only a proxy for the mixing process.

A comparison with 141 MLHs from radiosonde profiles showed better agreement with the wind-derived MLH than the aerosol-derived MLH (Sect. 2.3).

The uncertainty of the MLH retrieval from aerosol was estimated to be $5 \%$ by comparing MLHs from the Vaisala CT25K ceilometer with those from a more powerful Jenoptik CHM15K ceilometer (Sect. 2.1.4). The MLH retrieval from the vertical wind is based on a threshold for the standard deviation $\sigma_{w}$ of the vertical wind. Although the choice of the threshold can be justified by the semi-theoretical $\sigma_{w}$ profile of Lenschow et al. (1980) by assuming an average convective velocity scale $w_{\star}$, it is somewhat arbitrary. An alternative could be to search for the height where the $\sigma_{w}$ profile falls below a certain fraction of its maximum. This fraction could be derived from e.g. the Lenschow et al. (1980) profile (see equation B6), but from our experience especially the morning and late afternoon profiles deviate substantially from the theoretical profile (see also Sect. 2.2.2). As a result this method is less robust than the threshold method and we could show that a large change of the threshold by $25 \%$ changes the retrieved MLH by only $15 \%$ (Sect. 2.2.2).

The evaluation of the 1-year data shows that in general MLHs from both methods follow the typical evolution of a convective growing mixing layer. However, the method based on aerosol backscatter profiles typically overestimates the MLH throughout the day, and especially cannot follow the mixing-layer evolution in the morning and late afternoon hours (Sect. 3.2). This confirms earlier findings for aerosolbased MLH retrieval of the growing ML in the morning (e.g. Eresmaa et al., 2012) and its evening decay (e.g. Träumner et al., 2011). For the first time, the present study quantifies the average error of an aerosol-based MLH retrieval on a half-hourly basis. It is lowest (of the order of $100 \mathrm{~m}$ ) around noon and has distinct maxima in the morning (of the order of $300 \mathrm{~m}$ ) when the ML grows into the residual layer (RL) and in the late afternoon (of the order of $600 \mathrm{~m}$ ) when turbulence decays.

The reason for the morning overestimate is that during this time frequently no distinct backscatter gradient between the growing ML and the RL above is present (situation B in Fig. 4). An aerosol-based method finds either the top of the aerosol layer, which coincides with the top of the RL, or 
remaining aerosol layers within the RL. This also explains why the morning overestimate is smaller than in the afternoon.

In the late afternoon when turbulence decays, aerosol particles still remain well mixed and no clearly detectable gradient at the top of the descending mixing-layer top can be identified. Instead, any aerosol-based algorithm will continue to identify the top of the aerosol layer as MLH, which at this time of the day is already the top of the RL (situation $\mathrm{C}$ in Fig. 4).

Table 4 summarizes the performance of the two methods on days with convection and low cloud cover or clear sky conditions. Our analysis indicates that retrieving MLH with the backscatter-based method is more challenging than with the vertical velocity-based method. Although a MLH retrieval based on vertical wind seems at first sight simple there are some principal restrictions to be mentioned. During night vertical movement is suppressed in the stably stratified NBL. Nevertheless, strong wind shear due to e.g. the nocturnal low-level jet may lead to intermittent turbulence which is an occasional and locally constricted event (Van de Wiel et al., 2003). These events can cause effective mixing between layers, but might be missed with a vertically pointing instrument which can see only events at its own location.

Likewise, the late afternoon decay of the convective turbulence is a transition to a more intermittent regime, i.e. plumes which reach the top of the ML become less frequent. As a result $\sigma_{w}$ decays only gradually with time and the exact moment when the retrieval reports the breakdown of convective mixing depends strongly on the threshold. Due to the intermittent nature of the turbulence the standard deviation of vertical wind speed fluctuates in time and the retrieved MLH may jump between low and high values if the fluctuation is around the threshold. We also observed late afternoon cases when active plumes were advected in the upper two-thirds of the ABL only, while the lower third was calm. The retrieval then reported no MLH as no mixing between the surface and the layers above occurred. However, these cases are rare and in general the decay of $\sigma_{w}$ occurs similarly at all levels. In summary it can be said that it is principally not possible to determine the exact moment of the end of convective mixing and a different $\sigma_{w}$ threshold may shift the moment of detection. Nevertheless, a reduction of the $\sigma_{w}$ threshold by $25 \%$ is not sufficient to explain the difference between aerosol- and wind-derived MLH.

The systematic overestimation of MLH by the aerosolbased retrieval especially in the morning and afternoon hours has its effects on derived seasonal average ML characteristics: the aerosol-based MLH shows a maximum $(+200, \ldots,+500 \mathrm{~m})$ higher than that from the wind. It is reached on average $2.5 \mathrm{~h}$ later in the afternoon and average growth rates are smaller when compared with the windderived MLH. A comparison of the seasonal MLH maxima with those found by Baars et al. (2008) in Leipzig, central Europe, under similar climatic conditions, reveals sys- tematically larger MLHs from the ceilometer whereas the wind-derived MLHs agree very well. Nevertheless, differences are smaller than day-to-day variability. Average MLH growth rates are smaller than those reported by Baars et al. (2008) but this might be related to their retrieval: their data set was restricted to cloud-free conditions and due to the overlap function of their lidar they had to restrict to MLHs larger than $300 \mathrm{~m}$. Both of these restrictions prefer situations with higher growth rates, making a comparison difficult. Beside these retrieval-related differences it is unclear how large the year-to-year variability of MLH characteristics is. Many parameters influence the MLH development. Water vapour content and night-time cloud cover determine radiative cooling and thus how deep and how cold the NBL becomes and how long it takes to dissolve the NBL. Cloud cover during daytime strongly modulates the incoming solar radiation and thus energy available for ML growth. More precipitation means higher soil moisture, a higher latent heat flux at the surface at the cost of the sensible heat flux, and thus less intensive convection and lower MLHs. Another important parameter is the stratification of the free troposphere which limits growth rate and maximum height of the fully developed mixing layer.

As described by White et al. (2009), state-of-the-art dispersion models could be significantly improved by providing measured MLH as input. Ceilometers are widespread, e.g. at airports, and can provide continuous MLH estimates in networks (Haij et al., 2007; Haeffelin et al., 2012). We could show that aerosol-based MLH estimates suffer from systematical overestimation of the order of several hundred metres, especially in the morning and late afternoon hours when emissions from road traffic are largest. Concentrations of surface emitted pollutants in the mixing layer scale directly with the height of the ML. Accordingly, this overestimation significantly alters predictions of concentrations towards too low values.

MLH detection based on aerosol backscatter and any gradient method can provide reliable values only during noon hours when the convective boundary is fully developed, i.e. bounded by the clear air of the free troposphere, and as long as convection is active. MLH retrieval from vertical-pointing Doppler lidar as described here could be a valuable alternative. 


\section{Appendix A: Comparing ceilometers}

The key parameters to describe a lidar are wavelength $\lambda$, energy per pulse $E_{0}$, number of pulses averaged to one profile $N_{\mathrm{P}}$, opening area of the receiving telescope (aperture $A$ ), range gate length $(\Delta r)$ and beam diameter $(D)$. The receiver is usually an avalanche photodiode (APD, the semiconductor equivalent to a photomultiplier) which in principle counts single photons. Thus the number of typically sent and received photons is a good measure to compare two instruments.

The number of emitted photons $N_{0}$ is the energy per pulse $E_{\mathrm{P}}$ divided by the energy per photon $E_{0}$ which depends on wavelength $\lambda$ (Planck's relation): $E_{0}=h \cdot c / \lambda$, with Planck's constant $h$ and speed of light $c$, and thus $N_{0}=E_{\mathrm{P}} \cdot \lambda /(h \cdot c)$. For the average profile, $N_{\mathrm{m}}=N_{0} \cdot N_{\mathrm{P}}$ photons are emitted. Comparing two instruments $A$ and $B$ the relation between the emitted photons is

$\frac{N_{\mathrm{mA}}}{N_{\mathrm{mB}}}=\frac{E_{\mathrm{PA}} \cdot \lambda_{\mathrm{A}} \cdot N_{\mathrm{PA}}}{E_{\mathrm{PB}} \cdot \lambda_{\mathrm{B}} \cdot N_{\mathrm{PB}}}$.

The number of backscattered photons $N_{\beta}$ depends on the wavelength and the type of aerosol. The wavelength dependence can be estimated by a power law: $N_{\beta} \sim \lambda^{-v_{\text {mie }}}$ with Angstrom exponent $v_{\text {mie }}$ which is for continental aerosol typically of the order of $1, \ldots, 1.8$. The number also depends on the number of scattering particles and thus on size of the volume, i.e. range gate length $\Delta r$, and square of the beam diameter $D$, i.e. $N_{\beta} \sim \Delta r \cdot D^{2}$. Finally, only those photons that reach the telescope have a chance to be counted by the APD, thus it must be proportional to the aperture $(A)$. We thus get for the received photons $N_{\mathrm{r}}$ :

$\frac{N_{\mathrm{rA}}}{N_{\mathrm{rB}}}=\frac{E_{\mathrm{PA}} \cdot \lambda_{\mathrm{A}}^{1-v_{\text {mie }}} \cdot N_{\mathrm{PA}} \cdot \Delta r_{\mathrm{A}} \cdot D_{\mathrm{A}}^{2}}{E_{\mathrm{PB}} \cdot \lambda_{\mathrm{B}}^{1-v_{\text {mie }}} \cdot N_{\mathrm{PB}} \cdot \Delta r_{\mathrm{B}} \cdot D_{\mathrm{B}}^{2}}$.

Of course this estimate does not take into account the further pathway within the instrument, i.e. transmittance of the optics, bandwidth of the filters, sensitivity and dynamic range of the receiver, etc.

We operate two ceilometers at JOYCE: a Vaisala CT25K and a Jenoptik CHM15k with parameters depicted in Table 1. Although the Jenoptik emits nearly ten times more photons the number of potentially received photons per range gate is only 4.4 times larger than for the Vaisala. The main loss is due to the shorter range gate length. As the Jenoptik shows in general a much better sensitivity and less noise, it can be concluded that the receiver is better.

\section{Appendix B: The Lenschow profile}

Lenschow et al. (1980) derived a universal profile for $\sigma_{w}$ based on a handful of airplane measurements and scaling considerations. Scaling parameter for height should be the height of the convective mixing layer $h$. Velocity should scale with the convective velocity scale proposed by Deardorff (1970). Close to the surface the height dependence should be of the form $(z / h)^{1 / 3}$, at the surface $\sigma_{w}$ should be zero and the profile should have a maximum in the lower half of the convective mixing layer leading to the following form:

$\sigma_{w}=w_{\star} \cdot c_{1} \cdot \zeta^{\nu} \cdot\left(1-c_{2} \cdot \zeta\right)^{\mu}$

with $\zeta=z / h$ the height scaled with mixing-layer height $h$ and parameters $c_{1}=\sqrt{1.8}=1.34, c_{2}=0.8, v=\frac{1}{3}$ and $\mu=1$. At the top of the ML, at $\zeta=1$, the profile does not become zero - it is

$\sigma_{w \text { top }}=w_{\star} \cdot c_{1} \cdot\left(1-c_{2}\right)^{\mu}=0.268 \cdot w_{\star}$.

The derivative with respect to $\zeta$ is

$\frac{\partial \sigma_{w}}{\partial \zeta}=\sigma_{w} \cdot\left(\frac{\nu}{\zeta}-\frac{c_{2}}{1-c_{2} \zeta}\right)$.

At the maximum the derivative is zero, leading to

$\zeta_{\max }=\frac{v}{c_{2} \cdot(\mu+v)}=0.312$.

The value $\sigma_{w \max }$ at this height is

$\sigma_{w \max }=w_{\star} \cdot c_{1} \cdot \zeta_{\max }^{\nu} \cdot\left(1-c_{2} \cdot \zeta_{\max }\right)^{\mu}=0.682 \cdot w_{\star}$.

The value at ML top can be expressed relative to the value of the maximum:

$\sigma_{w \mathrm{top}}=\frac{1}{\zeta_{\max }^{\nu}} \cdot\left(\frac{1-c_{2}}{1-c_{2} \cdot \zeta_{\max }}\right)^{\mu}=0.393 \cdot \sigma_{w \max }$.

The profile can also be utilized to estimate the dependence of the MLH estimate from the threshold. Using $\frac{\partial \sigma_{w}}{\partial \zeta} \frac{1}{\sigma_{w}} \simeq \frac{\Delta \sigma_{w}}{\sigma_{w}} \frac{h}{\Delta z}$ at mixing-layer top $(\zeta=1)$ the relative change of determined MLH with a relative change of threshold $\sigma_{w \text { ts }}$ becomes

$$
\frac{\Delta \mathrm{MLH}}{\mathrm{MLH}}=\frac{1}{v-\frac{c_{2}}{1-c_{2}}} \cdot \frac{\Delta \sigma_{w \mathrm{ts}}}{\sigma_{w \mathrm{ts}}}=-0.273 \cdot \frac{\Delta \sigma_{w \mathrm{ts}}}{\sigma_{w \mathrm{ts}}} .
$$

That means that with an increase (decrease) of $\sigma_{w \mathrm{ts}}=0.4 \mathrm{~ms}^{-1}$ by $0.1 \mathrm{~ms}^{-1}$ (i.e. $25 \%$ ) the detected MLH decreases (increases) by $7 \%$. 
Acknowledgements. We gratefully acknowledge financial support by the SFB/TR 32 "Pattern in Soil-Vegetation-Atmosphere Systems: Monitoring, Modelling, and Data Assimilation" funded by the Deutsche Forschungsgemeinschaft (DFG). Work by A. Hirsikko was supported within the project High Definition Clouds and Precipitation for advancing Climate Prediction $\mathrm{HD}(\mathrm{CP})^{2}$ funded by the German Ministry for Education and Research (BMBF) under grant FK 01LK1209B. Radiosonde data came from the HOPEexperiment which is part of the $\mathrm{HD}(\mathrm{CP})^{2}$ project (BMBF grant 01LK1212F). We thank Martin Kohler for providing these data.

We thank Kerstin Ebell for proofreading the paper.

Edited by: L. Bianco

\section{References}

American Meteorological Society: Glossary of Meteorology, American Meteorological Society, http://glossary.ametsoc.org/, last access: 25 April 2014, 2013.

Augstein, E., Schmidt, H., and Wagner, V.: The vertical structure of the atmospheric planetary boundary layer in undisturbed Trade winds over the Atlantic Ocean, Bound-Lay. Meteorol., 6, 129150, doi:10.1007/BF00232480, 1974.

Baars, H., Ansmann, A., Engelmann, R., and Althausen, D.: Continuous monitoring of the boundary-layer top with lidar, Atmos. Chem. Phys., 8, 7281-7296, doi:10.5194/acp-8-7281-2008, 2008.

Banta, R. M., Pichugina, Yelena, L., and Brewerm, W. A.: Turbulent Velocity-Variance Profiles in the Stable Boundary Layer Generated by a Nocturnal Low-Level Jet, J. Atmos. Sci., 63, 27002719, doi:10.1175/JAS3776.1, 2006.

Barlow, J., F., Dunbar, T. M., Nemitz, E. G., Wood, C. R., Gallagher, M., Davies, F., O'Connor, E., and Harrison, R. M.: Boundary layer dynamics over London, UK, as observed using Doppler lidar during REPARTEE-II, Atmos. Chem. Phys., 11, 2111-2125, doi:10.5194/acp-11-2111-2011, 2011.

Brooks, I.: Finding boundary layer top: application of a wavelet covariance transform to lidar backscatter profiles, J. Atmos. Ocean. Tech., 20, 1092-1105, doi:10.1175/15200426(2003)020<1092:FBLTAO>2.0.CO;2, 2003.

Brown, A., Chlond, A., Golaz, C., Khairoutdinov, M., Lewellen, D., Lock, A., MacVean, M., Moeng, C.-H., Neggers, R., Siebesma, A., and Stevens, B.: Large-eddy simulation of the diurnal cycle of shallow cumulus convection over land, Quat. J. Roy. Meteorol. Soc., 128, 1075-1094, doi:10.1256/003590002320373210, 2002.

Brümmer, B., Lange, I., and Konow, H.: Atmospheric boundary layer measurements at the $280 \mathrm{~m}$ high Hamburg weather mast 1995-2011: mean annual and diurnal cycles, Meteorologische Zeitschrift, 21/4, 319-335, doi:10.1127/0941-2948/2012/0338, 2012.

Canny, J.: A Computational Approach to Edge Detection, IEEE Transactions on Pattern Analysis and Machine Intelligence (PAMI), 8, 679-698, doi:10.1109/TPAMI.1986.4767851, 1986.

Chen, W., Kuze, H., Uchiyama, A., Suzuki, Y., and Takeuchi, N.: One-year observation of urban mixed layer characteristics at Tsukuba, Japan using a micro pulse lidar, Atmos. Environ., 35, 4273-4280, doi:10.1016/S1352-2310(01)00181-9, 2001.
Cimini, D., De Angelis, F., Dupont, J.-C., Pal, S., and Haeffelin, M.: Mixing layer height retrievals by multichannel microwave radiometer observations, Atmos. Meas. Tech., 6, 2941-2951, doi:10.5194/amt-6-2941-2013, 2013.

Cohn, S. A. and Angevine, W. M.: Boundary Layer Height and Entrainment Zone Thickness Measured by Lidars and Wind-Profiling Radars, J. Appl. Meteorol., 39, 1233-1247, doi:10.1175/1520-0450(2000)039<1233:BLHAEZ>2.0.CO;2, 2000.

Collier, C., Davies, F., Bozier, K., Holt, A., Middleton, D., Pearson, G., Siemen, S., Willetts, D., Upton, G., and Young, R.: DualDoppler Lidar Measurements for Improving Dispersion Models, B. Am. Meteorol. Soc., 86, 825-838, doi:10.1175/BAMS-86-6825, 2005.

Davis, K., Gamage, N., Hagelberg, C., Kiemle, C., Lenschow, D., and Sullivan, P.: An objective method for deriving atmospheric structure from airborne lidar observations, J. Atmos. Ocean. Tech., 17, 1455-1468, doi:10.1175/15200426(2000)017<1455:AOMFDA>2.0.CO;2, 2000.

Deardorff, J.: Convective Velocity and Temperature Scales for the Unstable Plantery Boundary Layer and for Rayleigh Convection, J. Atmos. Sci., 27, 1211-1213, doi:10.1175/15200469(1970)027<1211:CVATSF>2.0.CO;2, 1970.

Deutscher Wetterdienst: Witterungsreport, 2011 and 2012.

Emeis, S., Schäfer, K., and Münkel, C.: Surface-based remote sensing of the mixing-layer height - a review, Meteorologische Zeitschrift, 17, 621-630, doi:10.1127/0941-2948/2008/0312, 2008.

Endlich, R., Ludwig, F., and Uthe, E.: An automatic method for determining the mixing depth from lidar observations, Atmos. Environ., 13, 1051-1056, doi:10.1016/0004-6981(79)90015-5, 1979.

Eresmaa, N., Karppinen, A., Joffre, S., Räsänen, J., and Talvitie, H.: Mixing height determination by ceilometer, Atmos. Chem. Phys., 6, 1485-1493, doi:10.5194/acp-6-1485-2006, 2006.

Eresmaa, N., Härkönen, J., Joffre, S., Schultz, D., Karppinen, A., and Kukkonen, J.: A Three-Step Method for Estimating the Mixing Height Using Ceilometer Data from the Helsinki Testbed, J. Appl. Meteorol. Climatol., 51, 2172-2187, doi:10.1175/JAMCD-12-058.1, 2012.

Garratt, J.: The Atmospheric Boundary Layer, Cambridge University Press, Cambridge, England, 1994.

Granados-Muñoz, M. J., Navas-Guzmán, F., Bravo-Aranda, J. A., Guerrero-Rascado, J. L., Lyamani, H., Fernández-Gálvez, J., and Alados-Arboledas, L.: Automatic determination of the planetary boundary layer height using lidar: One-year analysis over southeastern Spain, J. Geophys. Res. Atmos., 117, D18208, doi:10.1029/2012JD017524, 2012.

Haeffelin, M., Angelini, F., Morille, Y., Martucci, G., Frey, S., Gobbi, G. P., Lolli, S., O’Dowd, C. D., Sauvage, L., XuerefRémy, I.AND Wastine, B., and Feist, D. G.: Evaluation of Mixing-Height Retrievals from Automatic Profiling Lidars and Ceilometers in View of Future Integrated Networks in Europe, Bound-Lay. Meteorol., 143, 49-75, doi:10.1007/s10546-0119643-z, 2012.

Haij, M. d., Wauben, W., and Klein Baltink, H.: Determination of mixing layer height from ceilometer backscatter profiles, in: Proceedings of SPIE, edited by Slusser, J. R., Schäfer, K., and Comerón, A., vol. 6362, 63620R, doi:10.1117/12.691050, 2006. 
Haij, M. d., Wauben, W., and Klein Baltink, H.: Continuous mixing layer height determination using the LD-40 ceilometer: a feasibility study, Tech. Rep. KNMI Scientific Report WR 2007-01, KNMI, De Bilt, the Netherlands, 2007.

Harvey, N. J., Hogan, R. J., and Dacre, H. F.: Amethod to diagnose boundary-layer type using Doppler lidar, Quat. J. Roy. Meteorol. Soc., 139/676, 1681-1693, doi:10.1002/qj.2068, 2013.

Heese, B., Flentje, H., Althausen, D., Ansmann, A., and Frey, S.: Ceilometer lidar comparison: backscatter coefficient retrieval and signal-to-noise ratio determination, Atmos. Meas. Tech., 3, 1763-1770, doi:10.5194/amt-3-1763-2010, 2010.

Hennemuth, B. and Lammert, A.: Determination of the Atmospheric Boundary Layer Height from Radiosonde and Lidar Backscatter, Bound-Lay. Meteorol., 120, 181-200, doi:10.1007/s10546-005-9035-3, 2006.

Hogan, R., Grant, A., Illingworth, A., Pearson, G., and O'Connor, E.: Vertical velocity variance and skewness in clear and cloudtopped boundary layers as revealed by Doppler lidar, Quat. J. Roy. Meteorol. Soc., 135, 635-643, doi:10.1002/qj.413, 2009.

Korhonen, K., Giannakaki, E., Mielonen, T., Pfüller, A., Laakso, L., Vakkari, V., Baars, H., Engelmann, R., Beukes, J. P., Van Zyl, P. G., Ramandh, A., Ntsangwane, L., Josipovic, M., Tiitta, P., Fourie, G., Ngwana, I., Chiloane, K., and Komppula, M.: Atmospheric boundary layer top height in South Africa: measurements with lidar and radiosonde compared to three atmospheric models, Atmos. Chem. Phys., 14, 4263-4278, doi:10.5194/acp-14-42632014, 2014.

Lenschow, D., Lothon, M., Mayor, S., Sullivan, P., and Canut, G.: A Comparison of Higher-Order Vertical Velocity Moments in the Convective Boundary Layer from Lidar with In Situ Measurements and Large-Eddy Simulation, Bound-Lay. Meteorol., 143, 107-123, doi:10.1007/s10546-011-9615-3, 2012.

Lenschow, D. H., Wyngaard, J. C., and Pennell, W. T.: MeanField and Second-Moment Budgets in a Baroclinic, Convective Boundary Layer, J. Atmos. Sci., 37, 1313-1326, doi:10.1175/1520-0469(1980)037<1313:MFASMB>2.0.CO;2, 1980.

Lenschow, D. H., Wulfmeyer, V., and Senff, C.: Measuring second- through fourth-order moments in noisy data, J. Atmos. Ocean. Tech., 17/10, 1330-1347, doi:10.1175/15200426(2000)017<1330:MSTFOM>2.0.CO;2, 2000.

Löhnert, U. and Meier, O.: Operational profiling of temperature using ground-based microwave radiometry at Payerne: prospects and challenges, Atmos. Meas. Tech., 5, 1121-1134, doi:10.5194/amt-5-1121-2012, 2012.

Luo, T., Yuan, R., and Wang, Z.: Lidar-based remote sensing of atmospheric boundary layer height over land and ocean, Atmos. Meas. Tech., 7, 173-182, doi:10.5194/amt-7-173-2014, 2014.

Martucci, G., Milroy, C., and O'Dowd, C.: Detection of cloud-base height using Jenoptik CHM15K and Vaisala Cl31 Ceilometers, J. Atmos. Ocean. Tech., 27, 305-318, doi:10.1175/2009JTECHA1326.1, 2010.

Martucci, G., Chauvigne, A., O'Connor, E., J., Hirsikko, A., Ceburnis, D., Wobrock, W., and O'Dowd, C., D.: Ground-based remote sensing profiling of aerosols, boundary layer and liquid water clouds using synergistic retrievals, in: Proceedings of the 9th International Symposium on Tropospheric Profiling, L'Aquila, Italy, September 2012, http://cetemps.aquila.infn.it/istp/ proceedings/Session_C_Aerosols_clouds_and_precipitation/
Session_C_Tuesday_4_September_2012/SC_05_Martucci.pdf, last access: 25 April 2014, 2012.

Morille, Y., Haeffelin, M., Dobrinski, P., and Pelon, J.: STRAT: An Automated Algorithm to Retrieve the Vertical Structure of the Atmosphere from Single-Channel Lidar Data, J. Atmos. Ocean. Tech., 24, 761-775, doi:10.1175/JTECH2008.1, 2007.

Münkel, C., Eresmaa, N., Räsänen, J., and Karppinen, A.: Retrieval of mixing height and dust concentration with lidar ceilometer, Bound.-Lay. Meteorol., 124, 117-128, doi:10.1007/s10546-0069103-3, 2007.

Neggers, R. A. J., Siebesma, A. P., Lenderink, G., and Holtslag, A. A. M.: An Evaluation of Mass Flux Closures for Diurnal Cycles of Shallow Cumulus, Mon. Weather Rev., 132, 2525-2538, doi:10.1175/MWR2776.1, 2004.

Newsom, R.: Doppler Lidar (DL) Handbook, Tech. Rep. DOE/SCARM-TR-101, ARM Climate resarch facility, http://www.arm. gov/publications/tech_reports/handbooks/dl_handbook.pdf, last access: 25 April 2014, 2012.

Oke, T.: Boundary Layer Climates, Methuen \& Co., London, England, 1987.

O'Connor, E. J., Illingworth, Anthony, J., Brooks, Ian, M., Westbrook, Christopher, D., Hogan, Robin, J., Davies, F., and Brooks, Barbara, J.: A Method for Estimating the Turbulent Kinetic Energy Dissipation Rate from a Vertically Pointing Doppler Lidar, and Independent Evaluation from Balloon-Borne In Situ Measurements, J. Atmos. Ocean. Tech., 27, 1652-1664, doi:10.1175/2010JTECHA1455.1, 2010.

Pearson, G. and Collier, G.: A pulsed coherent $\mathrm{CO}_{2}$ lidar for boundary layer meteorology, Quat. J. Roy. Meteorol. Soc., 125, 27032721, doi:10.1002/qj.49712555918, 1999.

Pearson, G., Davies, F., and Collier, G.: Remote sensing of the tropical rain forest boundary layer using pulsed Doppler lidar, Atmos. Chem. Phys., 10, 5891-5901, doi:10.5194/acp-10-58912010, 2010.

Riehl, H., Yeh, C., Malkus, J., and LaSeur, N.: The northeast trade of the Pacific Ocean, Quat. J. Roy. Meteorol. Soc., 77, 598-626, doi:10.1002/qj.49707733405, 1951.

Rose, T., Crewell, S., Löhnert, U., and Simmer, C.: A network suitable microwave radiometer for operational monitoring of the cloudy atmosphere, Atmos. Res., 75, 183-200, doi:10.1016/j.atmosres.2004.12.005, 2005.

Rye, B. J. and Hardesty, R. M.: Discrete spectral peak estimation in incoherent backscatter heterodyne lidar. II: correlogram accumulation, IEEE Trans. Geosci. Remote Sens., 31, 28-35, doi:10.1109/36.210441, 1993.

Seibert, P., Beyrich, F., Gryning, S.-E., Joffre, S., Rasmussen, A., and Tercier, P.: Review and intercomparison of operational methods for the determination of the mixing height, Atmospheric Environment, 34, 1001-1027, doi:10.1016/S1352-2310(99)00349$0,2000$.

Senff, C., Bösenberg, J., Peters, G., and Schaberl, T.: Ozone Budget in the Convective Boundary Layer with DIAL and Radar-RASS A Case Study., Contrib. Atmos. Phys., 96, 161-176, http://cat. inist.fr/?aModele=afficheN\&cpsidt=3150665, 1996.

Sicard, M., Perez, C., Rocadenbosch, F., Baldasano, J., and García-Vizcaino, D.: Mixed-Layer Depth Determination in the Barcelona Coastal Area from Regular Lidar Measurements: Methods, Results and Limitations, Bound.-Lay. Meteorol., 119, 135-157, doi:10.1007/s10546-005-9005-9, 2006. 
Sorbjan, Z.: Structure of the atmospheric boundary layer, Prentice Hall, Engelwood Cliffs, New Jersey, USA, 1989.

Souch, C. and Grimmond, S.: Applied climatology: urban climate, Prog. Phys. Geogr., 30, 270-279, doi:10.1191/0309133306pp484pr, 2006.

Steyn, D., Baldi, M., and Hoff, R.: The detection of mixed layer depth and entrainment zone thickness from lidar backscatter profiles, J. Atmos. Ocean. Tech., 16, 953-959, doi:10.1175/15200426(1999)016<0953:TDOMLD>2.0.CO;2, 1999.

Stull, R. B.: An Introduction to Boundary Layer Meteorology, Kluwer Academic Publishers, Dordrecht, The Nederlands, 1988.

Taylor, G.: Diffusion by continous movements, Proceedings of the London Mathematical Society, 20, 196-212, doi:10.1112/plms/s2-20.1.101, 1922.

Taylor, G.: Statistical theory of turbulence part I-IV, P. Roy. Soc. Lond., 151, 421-478, doi:10.1098/rspa.1935.0158, 1935.

Träumner, K.: Einmischprozesse am Oberrand der konvektiven atmosphärischen Grenzschicht, Ph.D. thesis, Fakultät für Physik des Karlsruher Instituts für Technologie (KIT), http://www. imk-tro.kit.edu/4328_4862.php, 2010.

Träumner, K., Kottmeier, C., Corsmeier, U., and Wieser, A.: Convective Boundary-Layer Entrainment: Short Review and Progress using Doppler Lidar, Bound-Lay. Meteorol., 141, 369 391, doi:10.1007/s10546-011-9657-6, 2011.

Tucker, Sara, C., Senff, Christoph, J., Weickmann, Ann, M., Brewer, W., A., Banta, Robert, M., Sandberg, Scott, P., Law, Daniel, C., and Hardesty, R., M.: Doppler Lidar Estimation of Mixing Height Using Turbulence, Shear, and Aerosol Profiles, J. Atmos. Sci., 26, 673-688, doi:10.1175/2008JTECHA1157.1, 2009.

Vaisala: Ceilometer CT25K User's Guide, Helsinki, Finland, 1999.
Van de Wiel, B. J. H., Moene, A. F., Hartogensis, O. K., De Bruin, H. A. R., and Holtslag, A. A. M.: Intermittent Turbulence in the Stable Boundary Layer over Land. Part III: A Classification for Observations during CASES-99, J. Atmos. Sci., 60, 2509-2522, doi:10.1175/15200469(2003)060<2509:ITITSB>2.0.CO;2, 2003.

Weitkamp, C.: Lidar: Range-Resolved Optical Remote Sensing of the Atmosphere, Springer Series in Optical Sciences, Springer, New York, 2005.

White, J. M., Bowers, J. F., Hanna, S. R., and Lundquist, J. K.: Importance of Using Observations of Mixing Depths in order to Avoid Large Prediction Errors by a Transport and Dispersion Model, J. Atmos. Ocean. Tech., 26, 22-32, doi:10.1175/2008JTECHA1134.1, 2009.

Wiegner, M. and Geiß, A.: Aerosol profiling with the Jenoptik ceilometer CHM15kx, Atmos. Meas. Tech., 5, 1953-1964, doi:10.5194/amt-5-1953-2012, 2012.

Wiegner, M., Madonna, F., Binietoglou, I., Forkel, R., Gasteiger, J., Geiß, A., Pappalardo, G., Schäfer, K., and Thomas, W.: What is the benefit of ceilometers for aerosol remote sensing? An answer from EARLINET, Atmos. Meas. Tech., 7, 1979-1997, doi:10.5194/amt-7-1979-2014, 2014.

Xie, S., McCoy, Renata, B., Klein, Stephen, A., Cederwall, Richard, T., Wiscombe, Warren, J., Jensen, Michael, P., Johnson, Karen, L., Clothiaux, Eugene, E., Gaustad, Krista, L., Long, Charles, N., Mather, James, H., McFarlane, Sally, A., Shi, Y., Golaz, J.-C., Lin, Y., Hall, Stefanie, D., McCord, Raymond, A., Palanisamy, G., and Turner, David, D.: ARM climate modeling best estimate data, B. Am. Meteorol. Soc., 91, 13-20, doi:10.1175/2009BAMS2891.1, 2010. 